\title{
Caracterização florística de comunidades vegetais de restinga em Bertioga, SP, Brasil
}

\author{
Suzana Ehlin Martins ${ }^{1,3}$, Lucia Rossi ${ }^{1}$, Paulo de Salles Penteado Sampaio² e Mara Angelina Galvão Magenta ${ }^{2}$
}

Recebido em 25/10/2006. Aceito em 4/06/2007

\begin{abstract}
RESUMO - (Caracterização florística de comunidades vegetais de restinga em Bertioga, SP, Brasil). O município de Bertioga, no litoral central do Estado de São Paulo, apresenta grandes extensões de restingas ainda preservadas, com reduzido número de coletas de material botânico. A rápida devastação desse tipo de ambiente, por pressão de empreendedores do ramo imobiliário e outras intervenções antrópicas, torna urgente a compilação de dados que subsidiem estratégias conservacionistas. Nesse aspecto, é aqui apresentada a caracterização florística das comunidades vegetais da região que abrange as restingas de Itaguaré, São Lourenço e Guaratuba, situada entre

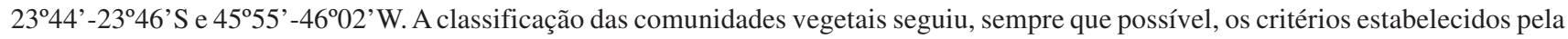
Resolução CONAMA n. 7/96, legislação ambiental federal, que aprova diretrizes para análise dos estágios de sucessão de vegetação de restinga para o Estado de São Paulo. Foram reconhecidas as comunidades vegetais de Praia e Dunas (33 espécies), Escrube (101), Floresta Alta de Restinga (301), Floresta Alta de Restinga Úmida (434) e Vegetação Entre Cordões (45). Foram registradas 611 espécies, representando 351 gêneros distribuídos em 106 famílias, das quais as de maior riqueza específica são: Orchidaceae (47 espécies), Myrtaceae (39), Bromeliaceae (36), Asteraceae (35), Rubiaceae (34), Fabaceae (32), Cyperaceae (23), Melastomataceae (19), Poaceae (19) e Solanaceae (15).
\end{abstract}

Palavras-chave: restinga, florística, comunidades vegetais, Bertioga

\begin{abstract}
Floristic characterization of "restinga" plant communities at Bertioga, São Paulo State, Brazil). The municipality of Bertioga, located on the central coast of São Paulo state, still has large areas of preserved 'restingas', where few botanical collections have been made. The rapidly growing devastation of this type of environment due to real-estate development and other human interventions makes urgent the need for data that support conservation strategies. For this reason, we characterize floristically the plant communities of the 'restingas' of Itaguaré, São Lourenço and Guaratuba (23⒋ $44^{\prime}-23^{\circ} 46^{\prime}$ S; $\left.45^{\circ} 55^{\prime}-46^{\circ} 02^{\prime} \mathrm{W}\right)$. Community classification followed, as closely as possible, the criteria established by Resolution n. 7/96 of the National Environment Council (CONAMA). The plant communities found were Beaches and Dunes (33 species), Scrub (101), Tall Restinga Forest (301), Tall Wet Restinga Forest (434) and Swale Vegetation (45). One-hundred-six families, 351 genera, 611 species were recorded, the most species-rich being: Orchidaceae (47 species), Myrtaceae (39), Bromeliaceae (36), Asteraceae (35), Rubiaceae (34), Fabaceae (32), Cyperaceae (23), Melastomataceae (19), Poaceae (19) and Solanaceae (15).
\end{abstract}

Key words: restinga, flora, plant communities, Bertioga

\section{Introdução}

O termo restinga possui diversos significados na literatura brasileira, que já foram bem explorados por Suguio \& Tessler (1984) e Suguio \& Martin (1990). Uma das formas de emprego do termo é no sentido botânico, segundo o qual ele representa o conjunto das comunidades vegetais fisionomicamente distintas, sob influência marinha e flúvio-marinha, ocorrendo sobre os depósitos arenosos costeiros (Araújo \& Henriques 1984; Cerqueira 2000).
No litoral Sudeste do Brasil, as escarpas de rochas do Complexo Cristalino Pré-Cambriano da Serra do Mar alcançam o mar em diversos locais. Assim, a costa sudeste é freqüentemente recortada, apresentando-se repleta de pequenas enseadas, com costões rochosos e praias estreitas (Araújo 1987; Suguio \& Tessler 1984). As planícies arenosas apresentam grande variedade de comunidades e espécies vegetais devido à diversidade de sua topografia e das condições ambientais que ali vicejam, incluindo influências marinhas e continentais (Araújo 1984). Com relação

\footnotetext{
1 Instituto de Botânica, C. Postal 3005, 01061-970 São Paulo, SP, Brasil

2 Universidade Santa Cecília, C. Postal 734, 11045-907 Santos, SP, Brasil

3 Autor para correspondência: suzanamartins@uol.com.br
} 
ao Estado de São Paulo, Souza et al. (1997) apresentaram um estudo no qual classificaram o litoral em sete setores, determinados pelas correlações entre as variações geológicas e geomorfológicas, e as diferenças fisionômicas da vegetação das planícies costeiras.

As classificações das fisionomias vegetais das restingas são, diversas vezes, muito simples e pouco precisas, outras conflitantes ou redundantes, provavelmente devido à falta de conhecimento de sua composição florística. Estudos recentes, propondo classificações para as diversas fisionomias, foram efetuados por Henriques et al. (1986), no Rio de Janeiro, Waechter (1990), no Rio Grande do Sul, e Pereira (1990), no Espírito Santo. Na classificação de Veloso et al. (1991) as diversas fisionomias de restinga estão englobadas na unidade "Formações Pioneiras com Influência Marinha". Recentemente, Silva \& Britez (2005) propuseram uma classificação fisionômica com base em critérios bastante objetivos e considerando a necessidade de se uniformizar a nomenclatura adotada, fortemente influenciada por abordagens regionais. No Estado de São Paulo foi estabelecida pelo Conselho Nacional do Meio Ambiente - CONAMA (1996) uma classificação que serve de embasamento legal para fins de controle ambiental e avaliação de impactos ao meio ambiente.

Diferentemente do litoral dos Estados do Rio de Janeiro e do Espírito Santo, que possuem diversos levantamentos de flora em restinga (Pereira \& Araújo 2000), as comunidades vegetais deste ambiente, no Estado de São Paulo, ainda não foram completamente estudadas. Os levantamentos florísticos e fitossociológicos existentes foram efetuados principalmente em unidades de conservação, e concentram-se no litoral sul, nos municípios de Peruíbe, Ilha Comprida, Iguape e Cananéia (De Grande \& Lopes 1981; Kirizawa et al. 1992; Sugiyama \& Mantovani 1993; Sugiyama 1998a, 1998b; Carvalhaes \& Mantovani 1998; Sztutman \& Rodrigues 2002; Souza \& Capellari Jr. 2004) e norte, nos municípios de Caraguatatuba e Ubatuba (Furlan et al. 1990; Mantovani 1992; Garcia \& Monteiro 1993; Ribeiro \& Monteiro 1993; Romero \& Monteiro 1993; Cesar \& Monteiro 1995; M.A. Assis, dados não publicados). Para o litoral central, as informações são ainda mais escassas, restringindo-se a descrições florísticas genéricas (Andrade \& Lamberti 1965), inventários florestais (França \& Rolim 2000) e estudos em fragmentos florestais (Girardi 2005; Guedes et al. 2006).

Lacerda \& Esteves (2000) consideram que as restingas, devido ao longo tempo de ocupação, encontram-se, de alguma maneira, alteradas, total ou parcialmente degradadas, tornando-se difícil, segundo Araújo (1984), identificar a vegetação primitiva destas planícies arenosas do litoral brasileiro. A Região Metropolitana da Baixada Santista não é diferente e vem apresentando uma acelerada urbanização, influenciada por atividades turísticas, portuárias e industriais, que colocam em risco a sobrevivência das florestas de restinga e dos morros isolados, na planície litorânea. Da totalidade das florestas de restinga originalmente existente nesta região restam, com estrutura fisionômica e composição florística preservadas, aproximadamente $22 \%\left(90 \mathrm{~km}^{2}\right)$. Deste total, $88 \mathrm{~km}^{2}$ situam-se em mancha praticamente contínua na porção setentrional da Planície de Bertioga. O restante, que corresponde a $323 \mathrm{~km}^{2}$ (78\%), está alterado por desmatamentos, extração de areia, influência da poluição industrial; sendo $162 \mathrm{~km}^{2}$ ocupados por estruturas urbanas, industriais e rurais (Silva et al. 1993).

Este levantamento visa contribuir para o conhecimento da região costeira do Estado, cobrindo a lacuna existente entre os litorais sul e norte e atender à demanda de informações que possam subsidiar estudos de impacto ambiental, projetos de manejo e conservação de áreas protegidas e a recuperação de áreas degradadas.

\section{Material e métodos}

O estudo foi realizado na região norte do município de Bertioga-SP, nas localidades denominadas Itaguaré, São Lourenço e Guaratuba, compreendidas entre as coordenadas geográficas $23^{\circ} 44^{\prime}-23^{\circ} 46^{\prime} \mathrm{S}$ e $45^{\circ} 55^{\prime}$ $46^{\circ} 02^{\prime} \mathrm{W}$.

Pelo sistema de Köppen, o clima da região pertence ao tipo "Af", tropical úmido ou super úmido, com chuvas distribuídas durante todo o ano (Setzer 1966). Segundo os dados climatológicos da estação meteorológica do DAEE, em Bertioga (2345,6'S, $46^{\circ} 04,2^{\prime} \mathrm{W}$ ), obtidos entre 1941 e 1970 , a temperatura média anual é de $24,8^{\circ} \mathrm{C}$, com média mensal mais baixa de $20,7{ }^{\circ} \mathrm{C}$ em julho e mais elevada de $28,3{ }^{\circ} \mathrm{C}$, em fevereiro. É uma das mais úmidas regiões do Brasil, com precipitação média de $3.200 \mathrm{~mm}$ anuais, com menor pluviosidade média em julho $(111 \mathrm{~mm})$ e maior em fevereiro $(410 \mathrm{~mm})$. No ano ocorre excedente hídrico de $1.796 \mathrm{~mm}$, não se observando períodos com déficit hídrico (Sentelhas et al. 1999).

Na região de estudo, as áreas de vegetação amostradas foram selecionadas por meio de consultas 
cartográficas, fotos aéreas e imagens de satélite, de forma a contemplar todas as fisionomias vegetais em bom estado de preservação e com condições de acesso para a coleta de material botânico. A vegetação desta região abrange o gradiente fisionômico e florístico desde as comunidades herbáceas de praia até as formações florestais de restinga, situadas próximas ao sopé da Serra do Mar.

Neste estudo, as formações vegetais foram analisadas, sempre que possível, segundo os critérios da Resolução CONAMA n. 7, de 23 de junho de 1996, utilizada oficialmente no Estado de São Paulo. Nesta Resolução, as classes são divididas em: Vegetação de Praias e Dunas, Vegetação Sobre Cordões Arenosos (Escrube, Floresta Baixa de Restinga, Floresta Alta de Restinga) e Vegetação Associada às Depressões (Entre Cordões Arenosos, Brejo de Restinga, Floresta Paludosa, Floresta Paludosa sobre Substrato Turfoso).

A região de Bertioga é representada por planícies costeiras de menor porte, com presença esparsa de restos de terraços marinhos pleistocênicos e sistemas fluviais atuais transversais e paralelos à linha de costa, estes últimos instalados sobre pequenas lagunas holocênicas colmatadas. A Vegetação de Praias é restrita a poucas áreas sem erosão praial. As fisionomias de Dunas, Brejo de Restinga e Floresta Paludosa ocorrem em áreas reduzidas, estando as duas últimas associadas a paleolagunas. A Floresta Baixa de Restinga desenvolve-se em faixa estreita paralela ao mar e às áreas ocupadas por vegetação entre cordões (Souza et al. 1997).

Embora represente o trecho mais bem preservado do litoral central de São Paulo, ainda assim apresenta alterações por intervenções antrópicas antigas, como o resquício da antiga estrada que ligava Bertioga a São Sebastião, atualmente com vegetação em regeneração, ou mais recentes, como os alagamentos provocados pela construção da rodovia Manoel Hipólito do Rego (Rio-Santos), na década de 1970, que alterou o fluxo das águas superficiais e subsuperficiais, além da extração de palmito (Euterpe edulis) e caxeta (Tabebuia cassinoides).

A área da praia de Itaguaré foi escolhida por abrigar uma das mais preservadas comunidades vegetais de restinga do litoral central do Estado de São Paulo, com exceção da porção sul, próxima à praia, que sofreu desmatamentos, para a implantação de condomínios residenciais e algumas alterações pontuais, como trilhas antigas e novas, essas últimas abertas para a prática de motociclismo. As áreas de Guaratuba e São Lourenço situadas, respectivamente, ao norte e ao sul de Itaguaré, encontram-se urbanizadas nos trechos próximos à praia; porém ocorrem áreas bastante preservadas em direção à Serra do Mar.

As coletas de material botânico constituídas exclusivamente por fanerógamas, foram efetuadas de agosto/1998 a abril/2002, percorrendo-se os caminhos e trilhas existentes, de modo a abranger a maior área possível e amostrar todas as fisionomias encontradas, com exceção de Florestas Paludosas e Brejos de Restinga, restritas a pequenas áreas da planície de inundação do rio Itaguaré com limitações de acesso e percorridas esporadicamente. As áreas degradadas por ação antrópica também tiveram a vegetação amostrada. As exsicatas estão depositadas no Herbário da Universidade Santa Cecília, com duplicatas no Herbário do Instituto de Botânica de São Paulo (SP).

A identificação das espécies foi realizada através de literatura específica, consulta a especialistas e comparação com material depositado no Herbário do Instituto de Botânica de São Paulo (SP). A listagem dos táxons foi organizada em ordem alfabética de família, gênero e espécie. Foi utilizado o sistema de classificação do APG II (2003).

Para cada espécie, foi indicada a forma biológica, classificada em arbórea (incluindo árvores, arvoretas e palmeiras), arbustiva (incluindo arbustos e subarbustos), herbácea (incluindo terrestres, saprófitas e aquáticas), epífita (incluindo hemi-epífita), liana (incluindo herbáceas e lenhosas) e hemiparasita. As ocorrências de espécies e formas biológicas foram comparadas com as de outros levantamentos em restinga do litoral Sul-Sudeste. Para avaliação de similaridade florística e freqüência dessas formas, foram considerados dois trabalhos com metodologia similar a este: S.M. Silva, dados não publicados, na Ilha do Mel, PR, e M.A. Assis, dados não publicados, em Picinguaba, SP.

Para a caracterização das diferentes fisionomias vegetais foram observados tipo de substrato, presença e altura da camada de serapilheira, altura dos estratos e suas principais espécies.

\section{Resultados e discussão}

Riqueza em espécies e formas de vida - Para o conjunto de locais estudados nas diferentes fitofisionomias da região de Bertioga, foi amostrado um total de 611 espécies pertencentes a 351 gêneros e 106 famílias. $\mathrm{Na}$ Tab. 1 são apresentadas todas as espécies amostradas, com a indicação da fisionomia de ocorrência e a forma biológica observada. A Tab. 2 
Tabela 1. Listagem dos táxons amostrados nas comunidades vegetais de restinga em Itaguaré, São Lourenço e Guaratuba - Bertioga (SP), Brasil, com correlação à forma biológica.

\begin{tabular}{|c|c|c|c|c|c|c|c|}
\hline \multirow[t]{2}{*}{ Família/Espécie } & \multirow[b]{2}{*}{$\begin{array}{c}\text { Praias } \\
\text { e dunas }\end{array}$} & \multicolumn{2}{|c|}{ Sobrecordões } & \multicolumn{2}{|c|}{ Depressões } & \multirow{2}{*}{$\begin{array}{c}\text { Forma } \\
\text { biológica }\end{array}$} & \multirow[t]{2}{*}{ Coletas } \\
\hline & & Escrube & Alta & $\begin{array}{l}\text { Entre } \\
\text { cordões }\end{array}$ & $\begin{array}{l}\text { Alta } \\
\text { úmida }\end{array}$ & & \\
\hline \multicolumn{8}{|l|}{ ACANTHACEAE } \\
\hline Aphelandra ornata (Nees) T. Anderson & & & & & $\mathrm{X}$ & herbácea & Martins 297, 322 \\
\hline A. prismatica (Vell.) Hieron. & & & & & $\mathrm{X}$ & herbácea & Bianchini 1255 \\
\hline Herpetacanthus aff. rubiginosus Nees & & & & $\mathrm{X}$ & $\mathrm{X}$ & herbácea & Sampaio 344, Martins 568 \\
\hline Hygrophila costata Nees & & & & & $\mathrm{X}$ & herbácea & Martins 410 \\
\hline Lepidagathis sp. & & & & $\mathrm{X}$ & $\mathrm{X}$ & herbácea & Martins 569 \\
\hline Justicia carnea Lindl. & & & & & $\mathrm{X}$ & herbácea & Anunciação 684, Sampaio 259 \\
\hline J. cf. schenckiana Lindau & & & $\mathrm{X}$ & & & herbácea & Magenta 87, Lima 01 \\
\hline Ruellia sp. & & & $\mathrm{X}$ & & $\mathrm{X}$ & herbácea & Rossi 2020, Martins 477 \\
\hline \multicolumn{8}{|l|}{ ALSTROEMERIACEAE } \\
\hline Bomarea edulis (Tussac) Herb. & & & $\mathrm{X}$ & & & liana & Sampaio 150, Anunciação 687 \\
\hline \multicolumn{8}{|l|}{ AMARANTHACEAE } \\
\hline $\begin{array}{l}\text { Blutaparon portulacoides (A. St.-Hil.) } \\
\text { Mears }\end{array}$ & $X$ & & & & & herbácea & Magenta 201 \\
\hline Cyathula prostrata (L.) Blume & & & & & $\mathrm{X}$ & herbácea & Rossi 2021 \\
\hline \multicolumn{8}{|l|}{ AMARYLLIDACEAE } \\
\hline Hippeastrum reticulatum (L'Hér.) Herb. & & & $\mathrm{X}$ & & & herbácea & Sampaio 470 \\
\hline \multicolumn{8}{|l|}{ ANACARDIACEAE } \\
\hline Schinus terebinthifolius Raddi & & $\mathrm{X}$ & $\mathrm{X}$ & & $\mathrm{X}$ & arbustiva & Sampaio 279, Magenta 152 \\
\hline Tapirira guianensis Aubl. & & & $\mathrm{X}$ & & $\mathrm{X}$ & arbórea & Martins 588, Magenta 229 \\
\hline \multicolumn{8}{|l|}{ ANNONACEAE } \\
\hline Annona glabra $\mathrm{L}$. & & & & & $\mathrm{X}$ & arbórea & Sampaio 431 \\
\hline Guatteria hilariana Schltdl. & & $\mathrm{X}$ & $\mathrm{X}$ & & $\mathrm{X}$ & arbórea & Rossi 2024, Sampaio 348 \\
\hline Rollinia sericea (R.E. Fr.) R.E. Fr. & & & $\mathrm{X}$ & & $\mathrm{X}$ & arbórea & Sampaio 192, 429 \\
\hline Xylopia brasiliensis Spreng. & & & $\mathrm{X}$ & & & arbórea & Martins 805 \\
\hline X. langsdorfiana A. St.-Hil.\& Tul. & & & $\mathrm{X}$ & & & arbórea & Martins 550, 596 \\
\hline \multicolumn{8}{|l|}{ APIACEAE } \\
\hline Centella asiatica (L.) Urb. & $\mathrm{X}$ & $\mathrm{X}$ & $\mathrm{X}$ & & $\mathrm{X}$ & herbácea & Rossi 2059 \\
\hline \multicolumn{8}{|l|}{ APOCYNACEAE } \\
\hline Condylocarpon isthmicum (Vell.) A. DC. & & & $\mathrm{X}$ & & $\mathrm{X}$ & liana & Martins 538, Sampaio 724 \\
\hline Forsteronia leptocarpa (Hook.\& Arn.) A. DC & & & & & $\mathrm{X}$ & liana & Sampaio 685, Martins 483 \\
\hline F. rufa Müll. Arg. & & & $\mathrm{X}$ & & & liana & Sampaio 577 \\
\hline $\begin{array}{l}\text { Gonioanthela axillaris (Vell.) Fontella \& } \\
\text { E.A. Schwarz }\end{array}$ & & & $\mathrm{X}$ & $\mathrm{X}$ & $\mathrm{X}$ & liana & Sampaio 730, Lima 08 \\
\hline Jobinia connivens (Hook. \& Arn.) Malme & $\mathrm{X}$ & & & & & liana & Martins 387 \\
\hline Mandevilla funiformis (Vell.) K. Schum. & & & $\mathrm{X}$ & & $\mathrm{X}$ & liana & Sampaio 162,621 \\
\hline $\begin{array}{l}\text { Matelea denticulata (Vahl) Fontella \& } \\
\text { E.A. Schwarz }\end{array}$ & & & & & $\mathrm{X}$ & liana & Martins 279 \\
\hline $\begin{array}{l}\text { Oxypetalum alpinum (Vell.) Fontella \& } \\
\text { E.A. Schwarz }\end{array}$ & & & & & $\mathrm{X}$ & liana & Sampaio 88, 561 \\
\hline O. banksii Schult. & & $\mathrm{X}$ & $\mathrm{X}$ & & & liana & Sampaio 680, 719 \\
\hline Peltastes peltatus (Vell.) Woodson & & & $\mathrm{X}$ & & $\mathrm{X}$ & liana & Martins 495, Magenta 237 \\
\hline Temnadenia odorifera (Vell.) J.F. Morales & & $\mathrm{X}$ & $\mathrm{X}$ & & & liana & Sampaio 699, Martins 472 \\
\hline \multicolumn{8}{|l|}{ AQUIFOLIACEAE } \\
\hline Ilex dumosa Reissek & & & & & $\mathrm{X}$ & arbórea & Martins 772, Sampaio 555 \\
\hline I. pseudobuxus Reissek & & & & $\mathrm{X}$ & $\mathrm{X}$ & arbórea & Sampaio 477, Lima 09 \\
\hline I. theezans Mart. ex Reissek & & $\mathrm{X}$ & $\mathrm{X}$ & & $\mathrm{X}$ & $\begin{array}{l}\text { arbórea / } \\
\text { arbustiva }\end{array}$ & Magenta 238, Sampaio 568 \\
\hline \multicolumn{8}{|l|}{ ARACEAE } \\
\hline Anthurium crassipes Engl. & & & $X$ & & $\mathrm{X}$ & $\begin{array}{l}\text { herbácea / } \\
\text { epífita }\end{array}$ & Martins 512, Sampaio 236 \\
\hline A. itanhaense Engl. & & $\mathrm{X}$ & $\mathrm{X}$ & & $\mathrm{X}$ & herbácea & Sampaio 304, Magenta 132 \\
\hline A. marense $\mathrm{K}$. Krause & & & $\mathrm{X}$ & & & herbácea & Martins 425,553 \\
\hline
\end{tabular}


Tabela 1 (continuação)

\begin{tabular}{|c|c|c|c|c|c|c|c|}
\hline \multirow[t]{2}{*}{ Família/Espécie } & \multirow[b]{2}{*}{$\begin{array}{l}\text { Praias } \\
\text { e dunas }\end{array}$} & \multicolumn{2}{|c|}{ Sobrecordões } & \multicolumn{2}{|c|}{ Depressões } & \multirow{2}{*}{$\begin{array}{c}\text { Forma } \\
\text { biológica }\end{array}$} & \multirow[t]{2}{*}{ Coletas } \\
\hline & & Escrube & Alta & $\begin{array}{l}\text { Entre } \\
\text { cordões }\end{array}$ & $\begin{array}{l}\text { Alta } \\
\text { úmida }\end{array}$ & & \\
\hline \multicolumn{2}{|l|}{ Anthurium pentaphyllum (Aubl.) G. Don } & & $\mathrm{X}$ & & $\mathrm{X}$ & epífita & Magenta 250, Martins 668 \\
\hline \multicolumn{2}{|l|}{ A. scandens (Aubl.) Engl. } & & & & $\mathrm{X}$ & epífita & Sampaio 126, Martins 511 \\
\hline \multicolumn{2}{|l|}{ Asterostigma lividum (Lodd.) Engl. } & & $\mathrm{X}$ & & & herbácea & Sampaio 349 \\
\hline \multicolumn{2}{|l|}{ Heteropsis rigidifolia Engl. } & & $\mathrm{X}$ & & & epífita & Sampaio 397 \\
\hline \multicolumn{2}{|l|}{ Monstera adansonii Schott } & & $\mathrm{X}$ & & $\mathrm{X}$ & epífita & Sampaio 237, 274 \\
\hline \multicolumn{2}{|l|}{ Philodendron appendiculatum Nadruz \& Mayo } & & & & $\mathrm{X}$ & epífita & Martins 582 \\
\hline \multicolumn{2}{|l|}{ P. bipinnatifidum Schott ex Endl. } & & $\mathrm{X}$ & & $\mathrm{X}$ & epífita & Rossi \\
\hline \multicolumn{2}{|l|}{$P$. corcovadense Kunth } & & & & $\mathrm{X}$ & epífita & Lima 32, Martins 284 \\
\hline \multicolumn{2}{|l|}{ P. crassinervium Lindl. } & & $\mathrm{X}$ & & $\mathrm{X}$ & epífita & Martins 760, Lima 44 \\
\hline \multicolumn{2}{|l|}{ P. aff. loefgrenii Engl. } & & $\mathrm{X}$ & & $\mathrm{X}$ & epífita & Martins 311,557 \\
\hline \multicolumn{2}{|l|}{ P. ochrostemon Schott } & & & & $X$ & epífita & Rossi 2018 \\
\hline ARALIACEAE & & & & & & & \\
\hline Dendropanax exilis (Toledo) S.L. Jung & & & $\mathrm{X}$ & & $\mathrm{X}$ & arbustiva & Magenta 131, Sampaio 241 \\
\hline Hydrocotyle bonariensis Lam. & $\mathrm{X}$ & & & & $\mathrm{X}$ & herbácea & Martins 633,643 \\
\hline H. leucocephala Cham. \& Schltdl. & & & & & $\mathrm{X}$ & herbácea & Martins 726 \\
\hline Oreopanax capitatus (Jacq.) Decne. \& Planch. & & & $\mathrm{X}$ & & $\mathrm{X}$ & arbórea & Sampaio 163 \\
\hline Schefflera angustissima (Marchal) Frodin & & & $\mathrm{X}$ & & $\mathrm{X}$ & arbórea & Martins 601, Sampaio 385 \\
\hline ARECACEAE & & & & & & & \\
\hline Astrocaryum aculeatissimum (Schott) Burret & & & $\mathrm{X}$ & & $\mathrm{X}$ & arbórea & \\
\hline Attalea dubia (Mart.) Burret & & & $\mathrm{X}$ & & $\mathrm{X}$ & arbórea & \\
\hline Bactris setosa Mart. & & & $\mathrm{X}$ & & $\mathrm{X}$ & arbórea & Lima 25 \\
\hline Euterpe edulis Mart. & & & $\mathrm{X}$ & & $\mathrm{X}$ & arbórea & Martins 583 \\
\hline Geonoma brevispatha Barb. Rodr. & & & $\mathrm{X}$ & & $\mathrm{X}$ & arbórea & Sampaio 191, Martins 716 \\
\hline G. pauciflora Mart. & & & & & $\mathrm{X}$ & arbórea & Martins 667 \\
\hline G. gamiova Barb. Rodr. & & & & & $\mathrm{X}$ & arbórea & Magenta 111 \\
\hline Syagrus pseudococos (Raddi) Glassman & & & $\mathrm{X}$ & & $\mathrm{X}$ & arbórea & \\
\hline S. romanzoffiana (Cham.) Glassman & & & $\mathrm{X}$ & & $X$ & arbórea & Martins 806 \\
\hline ASTERACEAE & & & & & & & \\
\hline Acanthospermum australe (Loefl.) Kuntze & $\mathrm{X}$ & & & & & herbácea & Martins 641 \\
\hline Achyrocline satureioides (Lam.) DC. & & & & $\mathrm{X}$ & $\mathrm{X}$ & herbácea & Sampaio 478 \\
\hline Acmella ciliata (Kunth) Cass. & & & & & $X$ & herbácea & Martins 899 \\
\hline Ambrosia elatior L. & $\mathrm{X}$ & & & & & herbácea & Martins 386 \\
\hline Baccharis conyzoides DC. & & & & & $\mathrm{X}$ & arbustiva & Sampaio 594, Martins 790 \\
\hline B. dracunculifolia DC. & & $\mathrm{X}$ & & & & arbustiva & Magenta 147 \\
\hline B. singularis (Vell.) G.M. Barroso & & & $X$ & & $X$ & arbustiva & Magenta 128, Sampaio 148 \\
\hline B. trimera (Less.) DC. & & & $\mathrm{X}$ & & $\mathrm{X}$ & herbácea & Martins 351,754 \\
\hline Centratherum punctatum Cass. & & $X$ & & & & herbácea & Sampaio 104, Martins 371 \\
\hline Conyza bonariensis (L.) Cronquist & & & & & $\mathrm{X}$ & herbácea & Sampaio 358, Magenta 244 \\
\hline Eclipta prostrata (L.) L. & & & $\mathrm{X}$ & & & herbácea & Magenta 120 \\
\hline Elephantopus mollis Kunth & & $\mathrm{X}$ & & & & herbácea & Sampaio 253, Martins 464 \\
\hline $\begin{array}{l}\text { Erechtites valerianaefolius (Link ex Spreng.) } \\
\text { DC. }\end{array}$ & & $\mathrm{X}$ & & $\mathrm{X}$ & & herbácea & Magenta 220 \\
\hline Mikania argyreiae DC. & & & $\mathrm{X}$ & & & liana & Martins 535, Sampaio 707 \\
\hline M. biformis DC. & & & $\mathrm{X}$ & & $\mathrm{X}$ & liana & Sampaio 711, Magenta 194 \\
\hline M. cordifolia (L. f.) Willd. & & $\mathrm{X}$ & $\mathrm{X}$ & & & liana & Sampaio 661,682 \\
\hline M. eriostrepta B.L. Rob. & & & & & $\mathrm{X}$ & liana & Sampaio 717 \\
\hline M. glomerata Spreng. & & $X$ & $\mathrm{X}$ & & & liana & Sampaio 709 \\
\hline M. hastato-cordata Malme & & $\mathrm{X}$ & & & & liana & Sampaio 305 \\
\hline M. involucrata Hook. \& Arn. & & $X$ & & & $\mathrm{X}$ & liana & Sampaio 552, 721 \\
\hline M. laevigata Sch. Bip. ex Baker & & $\mathrm{X}$ & $\mathrm{X}$ & & & liana & Sampaio 700 \\
\hline M. micrantha Kunth & & $\mathrm{X}$ & $\mathrm{X}$ & & $\mathrm{X}$ & liana & Magenta 96, Sampaio 674 \\
\hline M. rufescens Sch. Bip. ex Baker & & & & & $\mathrm{X}$ & liana & Sampaio 727 \\
\hline M. ternata (Vell.) B.L. Rob. & & $\mathrm{X}$ & & & $\mathrm{X}$ & liana & Martins 469 \\
\hline M. trinervis Hook. \& Arn. & & & & & $\mathrm{X}$ & liana & Magenta 192, Sampaio 703 \\
\hline Pentacalia desiderabilis (Vell.) Cuatrec. & & $X$ & & & & liana & Sampaio 270 \\
\hline
\end{tabular}


Tabela 1 (continuação)

\begin{tabular}{|c|c|c|c|c|c|c|c|}
\hline \multirow[t]{2}{*}{ Família/Espécie } & \multirow[b]{2}{*}{$\begin{array}{l}\text { Praias } \\
\text { e dunas }\end{array}$} & \multicolumn{2}{|c|}{ Sobrecordões } & \multicolumn{2}{|c|}{ Depressões } & \multirow{2}{*}{$\begin{array}{l}\text { Forma } \\
\text { biológica }\end{array}$} & \multirow[t]{2}{*}{ Coletas } \\
\hline & & Escrube & Alta & $\begin{array}{l}\text { Entre } \\
\text { cordões }\end{array}$ & $\begin{array}{l}\text { Alta } \\
\text { úmida }\end{array}$ & & \\
\hline Piptocarpha cf. cinerea Baker & & & & & $\mathrm{X}$ & arbórea & Martins 802 \\
\hline P. leprosa (Less.) Baker & & & $\mathrm{X}$ & & & liana & Martins 537, Sampaio 637 \\
\hline P. oblonga (Gardner) Baker & & & $\mathrm{X}$ & & $\mathrm{X}$ & liana & Martins 237, Sampaio 712 \\
\hline Pluchea laxiflora Hook. \& Arn. ex Baker & & & & & $\mathrm{X}$ & herbácea & Martins 862 \\
\hline Sphagneticola trilobata (L.) Pruski & $\mathrm{X}$ & $\mathrm{X}$ & $\mathrm{X}$ & & $\mathrm{X}$ & herbácea & Martins 494, Sampaio 412 \\
\hline Trixis divaricata (Kunth) Spreng. & & $\mathrm{X}$ & & & & arbustiva & Sampaio 303 \\
\hline Vernonia beyrichii Less. & & $\mathrm{X}$ & & & $\mathrm{X}$ & arbustiva & Sampaio 292, Magenta 143 \\
\hline V. puberula Less. & & & $\mathrm{X}$ & & $\mathrm{X}$ & $\begin{array}{c}\text { arbustiva / } \\
\text { arbórea }\end{array}$ & Martins 552, Magenta 213 \\
\hline V. scorpioides (Lam.) Pers. & & $\mathrm{X}$ & & $\mathrm{X}$ & & arbustiva & Martins 536, Rossi 2058 \\
\hline \multicolumn{8}{|l|}{ BEGONIACEAE } \\
\hline Begonia convolvulacea (Klotzsch) A. DC. & & & & & $\mathrm{X}$ & herbácea & Magenta137 \\
\hline B. fischeri Schrank & & & & & $\mathrm{X}$ & herbácea & Martins 458, 578 \\
\hline B. lanceolata Vell. & & & $\mathrm{X}$ & & $\mathrm{X}$ & epífita & Sampaio 343, Martins 592 \\
\hline B. radicans Vell. & & & & & $\mathrm{X}$ & epífita & Sampaio 109, Martins 357 \\
\hline \multicolumn{8}{|l|}{ BIGNONIACEAE } \\
\hline $\begin{array}{l}\text { Anemopaegma chamberlaynii (Sims) Bureau } \\
\text { \& K. Schum. }\end{array}$ & $X$ & & & & $\mathrm{X}$ & liana & Martins 389, Sampaio 608 \\
\hline Jacaranda puberula Cham. & & & $\mathrm{X}$ & & $\mathrm{X}$ & arbórea & Sampaio 351, Magenta 233 \\
\hline $\begin{array}{l}\text { Lundia virginalis var. nitidula (DC.) } \\
\text { A.H. Gentry }\end{array}$ & & & $X$ & & $X$ & liana & Lima 15, Sampaio 720 \\
\hline Parabignonia unguiculata (Vell.) A.H. Gentry & & & $\mathrm{X}$ & & $\mathrm{X}$ & liana & Sampaio 705, Magenta 235 \\
\hline Tabebuia cf. alba (Cham.) Sandwith & & & $\mathrm{X}$ & & & arbórea & Martins 621 \\
\hline T. cassinoides (Lam.) DC. & & & $\mathrm{X}$ & & $\mathrm{X}$ & arbórea & Magenta 214 \\
\hline T. heptaphylla (Vell.) Toledo & & & & & $\mathrm{X}$ & arbórea & Martins 710 \\
\hline T. obtusifolia (Cham.) Bureau & & & & & $\mathrm{X}$ & arbórea & Magenta 232, Martins 564 \\
\hline T. umbellata (Sond.) Sandwith & & & & & $\mathrm{X}$ & arbórea & Lima 02, Sampaio 543 \\
\hline \multicolumn{8}{|l|}{ BORAGINACEAE } \\
\hline Cordia curassavica (Jacq.) Roem. \& Schult. & & $\mathrm{X}$ & $\mathrm{X}$ & & $\mathrm{X}$ & arbustiva & Martins 540, Sampaio 432 \\
\hline C. sellowiana Cham. & & $\mathrm{X}$ & & & $\mathrm{X}$ & $\begin{array}{l}\text { arbustiva / } \\
\text { arbórea }\end{array}$ & Sampaio 450, Martins 509 \\
\hline Tournefortia gardneri A. DC. & & & $\mathrm{X}$ & & & liana & Sampaio 441 \\
\hline \multicolumn{8}{|l|}{ BRASSICACEAE } \\
\hline Cleome rosea Vahl ex DC. & & & & & $\mathrm{X}$ & herbácea & Martins 732 \\
\hline \multicolumn{8}{|l|}{ BROMELIACEAE } \\
\hline Aechmea nudicaulis (L.) Griseb. & & & $\mathrm{X}$ & & $\mathrm{X}$ & epífita & Sampaio 165, Magenta 84 \\
\hline A. organensis Wawra & & & & & $\mathrm{X}$ & epífita & Martins 286, Sampaio 365 \\
\hline A. pectinata Baker & & & $\mathrm{X}$ & & $\mathrm{X}$ & $\begin{array}{l}\text { herbácea / } \\
\text { epífita }\end{array}$ & Sampaio 194, Magenta 85 \\
\hline Ananas fritzmuelleri Camargo & & $\mathrm{X}$ & $\mathrm{X}$ & & & herbácea & Martins 245, 366 \\
\hline Billbergia amoena (Lodd.) Lindl. & & & $\mathrm{X}$ & & $\mathrm{X}$ & $\begin{array}{l}\text { herbácea / } \\
\text { epífita }\end{array}$ & Magenta 127, Sampaio 301 \\
\hline B. pyramidalis (Sims) Lindl. & & & & & $\mathrm{X}$ & herbácea & Martins 719 \\
\hline Bromelia antiacantha Bertol. & & $\mathrm{X}$ & $\mathrm{X}$ & & & $\begin{array}{l}\text { herbácea / } \\
\text { epífita }\end{array}$ & Martins 378 \\
\hline Canistrum perplexum L.B. Sm. & & & $\mathrm{X}$ & & & epífita & Sampaio 346, 527 \\
\hline $\begin{array}{l}\text { Catopsis berteroniana (Schult. \& } \\
\text { Schult. f.) Mez }\end{array}$ & & & & & $\mathrm{X}$ & epífita & Martins 756, 864 \\
\hline C. sessiliflora (Ruiz \& Pav.) Mez & & & $\mathrm{X}$ & & & epífita & Martins 658 \\
\hline Neoregelia laevis (Mez) L.B. Sm. & & & & & $\mathrm{X}$ & epífita & Martins 302 \\
\hline N. marmorata (Baker) L.B. Sm. & & & $\mathrm{X}$ & & $\mathrm{X}$ & epífita & Martins 638, Sampaio 558 \\
\hline Nidularium billbergioides (Schult. f.) L.B. Sm. & & & & & $\mathrm{X}$ & epífita & Martins 298 \\
\hline N. burchellii (Baker) Mez & & & $X$ & & $\mathrm{X}$ & epífita & Lima 05, Sampaio 481 \\
\hline N. innocentii Lem. & & $\mathrm{X}$ & $\mathrm{X}$ & & $\mathrm{X}$ & $\begin{array}{l}\text { herbácea / } \\
\text { epífita }\end{array}$ & Sampaio 275, Martins 455 \\
\hline
\end{tabular}


Tabela 1 (continuação)

\begin{tabular}{|c|c|c|c|c|c|c|c|}
\hline \multirow[t]{2}{*}{ Família/Espécie } & \multirow[b]{2}{*}{$\begin{array}{c}\text { Praias } \\
\text { e dunas }\end{array}$} & \multicolumn{2}{|c|}{ Sobrecordões } & \multicolumn{2}{|c|}{ Depressões } & \multirow{2}{*}{$\begin{array}{c}\text { Forma } \\
\text { biológica }\end{array}$} & \multirow[t]{2}{*}{ Coletas } \\
\hline & & Escrube & Alta & $\begin{array}{l}\text { Entre } \\
\text { cordões }\end{array}$ & $\begin{array}{l}\text { Alta } \\
\text { úmida }\end{array}$ & & \\
\hline Nidularium procerum Lindm. & & & $\mathrm{X}$ & & $\mathrm{X}$ & $\begin{array}{l}\text { herbácea / } \\
\text { epífita }\end{array}$ & Magenta 208, Sampaio 267 \\
\hline Quesnelia arvensis (Vell.) Mez & & $\mathrm{X}$ & $X$ & & $\mathrm{X}$ & $\begin{array}{l}\text { herbácea / } \\
\text { epífita }\end{array}$ & Martins 316, Sampaio 298 \\
\hline Q. marmorata (Lem.) Read & & & & & $\mathrm{X}$ & epífita & Magenta 249, Sampaio 339 \\
\hline $\begin{array}{l}\text { Racinaea spiculosa (Griseb.) M.A. } \\
\text { Spencer \& L.B. Sm. }\end{array}$ & & & $\mathrm{X}$ & $\mathrm{X}$ & $\mathrm{X}$ & epífita & Martins 598, Lima 43 \\
\hline Tillandsia dura Baker & & & $\mathrm{X}$ & & $X$ & epífita & Martins 684, Sampaio 529 \\
\hline T. gardneri Lindl. & & & $\mathrm{X}$ & & $X$ & epífita & Lima 49, Martins 507 \\
\hline T. geminiflora Brongn. & & & & & $\mathrm{X}$ & epífita & Martins 230, 283 \\
\hline T. globosa Wawra & & & & & $X$ & epífita & Martins 572, Sampaio 149 \\
\hline T. aff. stricta Sol. ex Sims & & & & & $X$ & epífita & Martins, 751 \\
\hline T. tenuifolia $\mathrm{L}$. & & & $X$ & & $\mathrm{X}$ & epífita & Martins 682,757 \\
\hline T. usneoides (L.) L. & & & $X$ & & $X$ & epífita & Sampaio 453 \\
\hline Vriesea carinata Wawra & & & $\mathrm{X}$ & & $X$ & epífita & Martins 412, Magenta 326 \\
\hline V. ensiformis (Vell.) Beer & & & $X$ & & $\mathrm{X}$ & epífita & Sampaio 396, Martins 454 \\
\hline $\begin{array}{l}\text { V. erythrodactylon (E. Morren) } \\
\text { E. Morren ex Mez }\end{array}$ & & & & & $\mathrm{X}$ & epífita & Sampaio 384 \\
\hline V. flammea L.B.Sm. & & & & $\mathrm{X}$ & $\mathrm{X}$ & $\begin{array}{l}\text { herbácea / } \\
\text { epífita }\end{array}$ & Martins 345, Lima 33 \\
\hline V. gigantea Gaudich. & & & $\mathrm{X}$ & & $\mathrm{X}$ & epífita & Sampaio 750 \\
\hline$V$. aff. incurvata Gaudich. & & & & & $\mathrm{X}$ & epífita & Sampaio 110, 345 \\
\hline V. procera (Mart. ex Schult. f.) Wittm. & & & $\mathrm{X}$ & & $\mathrm{X}$ & epífita & Sampaio 296 \\
\hline V. rodigasiana $\mathrm{E}$. Morren & & & & & $X$ & epífita & Magenta 99, Sampaio 556 \\
\hline V. simplex (Vell.) Beer & & & $\mathrm{X}$ & & $X$ & epífita & Martins 241, Sampaio 550 \\
\hline V. vagans (L.B. Sm.) L.B. Sm. & & & $\mathrm{X}$ & & $\mathrm{X}$ & epífita & Lima 42, Martins 691 \\
\hline \multicolumn{8}{|l|}{ BURMANNIACEAE } \\
\hline $\begin{array}{l}\text { Burmannia capitata (Walter ex J.F. Gmel.) } \\
\text { Mart. }\end{array}$ & & & $\mathrm{X}$ & & & herbácea & Martins 488 \\
\hline $\begin{array}{l}\text { Gymnosiphon divaricatus (Benth.) } \\
\text { Benth. \& Hook. f. }\end{array}$ & & & $\mathrm{X}$ & & & herbácea & Sampaio 476 \\
\hline \multicolumn{8}{|l|}{ CACTACEAE } \\
\hline Lepismium cruciforme (Vell.) Miq. & & & & & $\mathrm{X}$ & epífita & Martins 664 \\
\hline Rhipsalis oblonga Loefgr. & & & & & $\mathrm{X}$ & epífita & Sampaio 491 \\
\hline R. pulvinigera $\mathrm{G}$. Lindb. & & & & & $\mathrm{X}$ & epífita & Martins 669 \\
\hline R. teres (Vell.) Steud. & & & $\mathrm{X}$ & & $\mathrm{X}$ & epífita & Martins 510, Sampaio 248 \\
\hline \multicolumn{8}{|l|}{ CALYCERACEAE } \\
\hline Acicarpha spathulata $\mathrm{R} . \mathrm{Br}$. & $\mathrm{X}$ & & & & & herbácea & Martins 388, 721 \\
\hline \multicolumn{8}{|l|}{ CAMPANULACEAE } \\
\hline Centropogon cornutus (L.) Druce & & & & $\mathrm{X}$ & $\mathrm{X}$ & herbácea & Sampaio 256, Martins 282 \\
\hline \multicolumn{8}{|l|}{ CANNABACEAE } \\
\hline Trema micrantha (L.) Blume & & & $\mathrm{X}$ & & & arbórea & Sampaio 468 \\
\hline \multicolumn{8}{|l|}{ CELASTRACEAE } \\
\hline Cheiloclinium cognatum (Miers) A.C. Sm. & & & & & $\mathrm{X}$ & arbustiva & Martins 809 \\
\hline Elachyptera micrantha (Cambess.) A.C. Sm. & & & & & $\mathrm{X}$ & liana & Martins 666, Sampaio 611 \\
\hline Hippocratea volubilis L. & & & & & $X$ & liana & Sampaio 484 \\
\hline Maytenus littoralis Carvalho-Okano & & $\mathrm{X}$ & $\mathrm{X}$ & & $\mathrm{X}$ & $\begin{array}{l}\text { arbustiva / } \\
\text { arbórea }\end{array}$ & Sampaio 169, Magenta 184 \\
\hline M. robusta Reissek & & $\mathrm{X}$ & $\mathrm{X}$ & & $\mathrm{X}$ & arbórea & Magenta 196, Rossi 2055 \\
\hline M. schumanniana Loes. & & & & & $\mathrm{X}$ & $\begin{array}{l}\text { arbustiva / } \\
\text { arbórea }\end{array}$ & Sampaio 539 \\
\hline Peritassa hatschbachii Lombardi & & & & & $\mathrm{X}$ & liana & Martins 698, Sampaio 589 \\
\hline \multicolumn{8}{|l|}{ CHLORANTHACEAE } \\
\hline Hedyosmum brasiliense Mart. ex Miq. & & & & & $\mathrm{X}$ & arbustiva & Martins 236, Sampaio 157 \\
\hline
\end{tabular}


Tabela 1 (continuação)

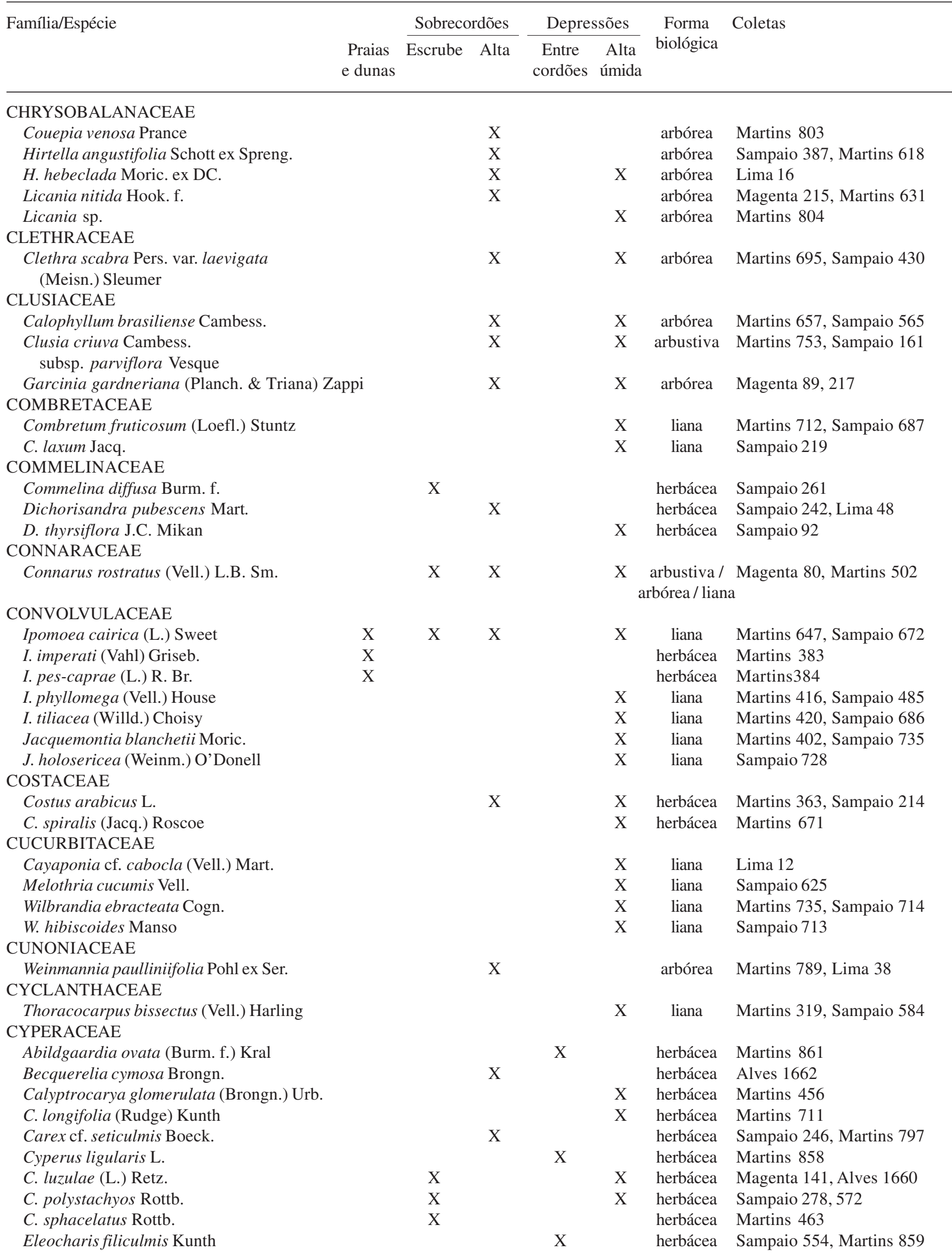


Tabela 1 (continuação)

\begin{tabular}{|c|c|c|c|c|c|c|c|}
\hline \multirow[t]{2}{*}{ Família/Espécie } & \multirow[b]{2}{*}{$\begin{array}{l}\text { Praias } \\
\text { e dunas }\end{array}$} & \multicolumn{2}{|c|}{ Sobrecordões } & \multicolumn{2}{|c|}{ Depressões } & \multirow{2}{*}{$\begin{array}{l}\text { Forma } \\
\text { biológica }\end{array}$} & \multirow[t]{2}{*}{ Coletas } \\
\hline & & Escrube & Alta & $\begin{array}{l}\text { Entre } \\
\text { cordões }\end{array}$ & $\begin{array}{l}\text { Alta } \\
\text { úmida }\end{array}$ & & \\
\hline Eleocharis geniculata (L.) Roem. \& Schult. & & & & $X$ & & herbácea & Martins 740 \\
\hline E. nana Kunth & & & & $\mathrm{X}$ & & herbácea & Martins 573 \\
\hline Fimbristylis autumnalis (L.) Roem. \& Schult. & & & & & $\mathrm{X}$ & herbácea & Martins 788 \\
\hline F. miliacea $(\mathrm{L}$.$) Vahl$ & & & & $\mathrm{X}$ & & herbácea & Sampaio 570, Martins 860 \\
\hline Fuirena umbellata Rottb. & & & & & $\mathrm{X}$ & herbácea & Martins 708 \\
\hline Hypolytrum schraderianum Nees & & & $\mathrm{X}$ & & & herbácea & Sampaio 138, Alves 1663 \\
\hline Kyllinga vaginata Lam. & $\mathrm{X}$ & $\mathrm{X}$ & & & & herbácea & Magenta 253 \\
\hline Rhynchospora corymbosa (L.) Britton & & & & $\mathrm{X}$ & & herbácea & Sampaio 564 \\
\hline R. holoschoenoides (Rich.) Herter & & & & $\mathrm{X}$ & & herbácea & Alves 1651 \\
\hline R. rugosa (Vahl) Gale & & & $\mathrm{X}$ & & & herbácea & Alves 1650 \\
\hline R. tenerrima Nees ex Spreng. & & & & $X$ & & herbácea & Martins 741 \\
\hline Scleria myricocarpa Kunth & & & $\mathrm{X}$ & & & herbácea & Alves 1661 \\
\hline S. pterota C. Presl & & & & & $\mathrm{X}$ & herbácea & Sampaio 559 \\
\hline \multicolumn{8}{|l|}{ DILLENIACEAE } \\
\hline Doliocarpus glomeratus Eichler & & $\mathrm{X}$ & $\mathrm{X}$ & & $\mathrm{X}$ & liana & Magenta 92, 252 \\
\hline Tetracera sellowiana Schltdl. & & $\mathrm{X}$ & $\mathrm{X}$ & & $\mathrm{X}$ & liana & Magenta 144, Sampaio 734 \\
\hline \multicolumn{8}{|l|}{ DIOSCOREACEAE } \\
\hline Dioscorea altissima Lam. & & & $\mathrm{X}$ & & & liana & Martins 619 \\
\hline D. glandulosa Klotsch ex Kunth & & & $X$ & & $\mathrm{X}$ & liana & Martins 635, Sampaio 725 \\
\hline D. monadelpha (Kunth) Griseb. & & $\mathrm{X}$ & $\mathrm{X}$ & & $\mathrm{X}$ & liana & Rossi 2017, Sampaio 726 \\
\hline \multicolumn{8}{|l|}{ DROSERACEAE } \\
\hline Drosera capillaris Poir. & & & & $X$ & & herbácea & Sampaio 145 \\
\hline \multicolumn{8}{|l|}{ EBENACEAE } \\
\hline Diospyros brasiliensis Mart. ex Miq. & & & & & $\mathrm{X}$ & arbórea & Rossi 2022, Sampaio 488 \\
\hline \multicolumn{8}{|l|}{ ELAEOCARPACEAE } \\
\hline Sloanea guianensis (Aubl.) Benth. & & & $\mathrm{X}$ & & $\mathrm{X}$ & arbórea & Lima 03, Sampaio 356 \\
\hline \multicolumn{8}{|l|}{ ERICACEAE } \\
\hline Gaylussacia brasiliensis (Spreng.) Meisn. & & & & & $\mathrm{X}$ & arbustiva & Sampaio 571 \\
\hline \multicolumn{8}{|l|}{ ERIOCAULACEAE } \\
\hline Syngonanthus chrysanthus (Bong.) Ruhland & & & $\mathrm{X}$ & $\mathrm{X}$ & & herbácea & Sampaio 475, Martins 597 \\
\hline Tonina fluviatilis Aubl. & & & & $\mathrm{X}$ & $\mathrm{X}$ & herbácea & Martins 703, Sampaio 534 \\
\hline \multicolumn{8}{|l|}{ ERYTHROXYLACEAE } \\
\hline $\begin{array}{l}\text { Erythroxylum amplifolium (Mart.) } \\
\text { O.E. Schulz }\end{array}$ & & & & & $\mathrm{X}$ & arbustiva & Martins 807 \\
\hline E. cuspidifolium Mart. & & & $\mathrm{X}$ & & & $\begin{array}{c}\text { arbustiva / } \\
\text { arbórea }\end{array}$ & Sampaio 152, Martins 599 \\
\hline \multicolumn{8}{|l|}{ EUPHORBIACEAE } \\
\hline Actinostemon concolor (Spreng.) Müll. Arg. & & & & & $\mathrm{X}$ & arbórea & Magenta 167, Martins 529 \\
\hline Alchornea triplinervia (Spreng.) Müll. Arg. & & & $\mathrm{X}$ & & $\mathrm{X}$ & arbórea & Magenta 245, Anunciação 680 \\
\hline Aparisthmium cordatum (A. Juss.) Baill. & & & $\mathrm{X}$ & & & arbórea & Martins 350, Magenta 122 \\
\hline Croton glandulosus L. & & & & & $\mathrm{X}$ & arbustiva & Martins 702 \\
\hline C. sphaerogynus Baill. & & & & & $\mathrm{X}$ & liana & Martins 565 \\
\hline Dalechampia leandrii Baill. & & & $\mathrm{X}$ & & & liana & Magenta 83 \\
\hline Maprounea guianensis Aubl. & & & $\mathrm{X}$ & & $\mathrm{X}$ & arbórea & Sampaio 549, Martins 786 \\
\hline Pera glabrata (Schott) Poepp. ex Baill. & & & $\mathrm{X}$ & & $\mathrm{X}$ & arbórea & Sampaio 407, Martins 632 \\
\hline Sapium glandulatum (Vell.) Pax & & & & & $\mathrm{X}$ & arbórea & Martins 812 \\
\hline Sebastiania corniculata (Vahl) Müll. Arg. & $\mathrm{X}$ & $\mathrm{X}$ & $X$ & & $\mathrm{O}$ & $\begin{array}{l}\text { herbácea / } \\
\text { liana }\end{array}$ & Anunciação 665, Sampaio 414 \\
\hline Tetraplandra riedelii Müll. Arg. & & & $\mathrm{X}$ & & & arbórea & Sampaio 440, Martins 594 \\
\hline \multicolumn{8}{|l|}{ FABACEAE } \\
\hline $\begin{array}{l}\text { Abarema brachystachya (DC.) Barneby } \\
\text { \& J.W. Grimes }\end{array}$ & & & $\mathrm{X}$ & & $\mathrm{X}$ & arbórea & Magenta 247, Sampaio 265 \\
\hline Andira fraxinifolia Benth. & & & $\mathrm{X}$ & & $\mathrm{X}$ & arbórea & Sampaio 199 \\
\hline Balizia pedicellaris (DC.) Barneby & & & $\mathrm{X}$ & & $\mathrm{X}$ & arbórea & Sampaio 84, Martins 616 \\
\hline
\end{tabular}


Tabela 1 (continuação)

\begin{tabular}{|c|c|c|c|c|c|c|c|}
\hline \multirow[t]{2}{*}{ Família/Espécie } & \multirow[b]{2}{*}{$\begin{array}{l}\text { Praias } \\
\text { e dunas }\end{array}$} & \multicolumn{2}{|c|}{ Sobrecordões } & \multicolumn{2}{|c|}{ Depressões } & \multirow{2}{*}{$\begin{array}{l}\text { Forma } \\
\text { biológica }\end{array}$} & \multirow[t]{2}{*}{ Coletas } \\
\hline & & Escrube & Alta & $\begin{array}{l}\text { Entre } \\
\text { cordões }\end{array}$ & $\begin{array}{l}\text { Alta } \\
\text { úmida }\end{array}$ & & \\
\hline Calopogonium mucunoides Desv. & & & & & $\mathrm{X}$ & liana & Magenta 160 \\
\hline Centrosema virginianum (L.) Benth. & $\mathrm{X}$ & $\mathrm{X}$ & & & & $\begin{array}{l}\text { herbácea / } \\
\text { liana }\end{array}$ & Sampaio 576, 622 \\
\hline Chamaecristaflexuosa (L.) Greene & & & $\mathrm{X}$ & & & herbácea & Magenta 148, 203 \\
\hline $\begin{array}{l}\text { C. ramosa (Vogel) H.S. Irwin \& } \\
\text { Barneby }\end{array}$ & & $\mathrm{X}$ & $\mathrm{X}$ & & & herbácea & Magenta 204, Martins 479 \\
\hline Crotalaria vitellina Ker Gawl. & & $\mathrm{X}$ & & & $\mathrm{X}$ & herbácea & Anunciação 685, Martins 391 \\
\hline Dalbergia ecastaphyllum (L.) Taub. & $X$ & $\mathrm{X}$ & & & & arbustiva & Martins 642 \\
\hline D. frutescens (Vell.) Britton & & & & & $\mathrm{X}$ & liana & Sampaio 313, 629 \\
\hline D. sampaioana Kuhlm. \& Hoehne & & & & & $\mathrm{X}$ & liana & Sampaio 312, Magenta 234 \\
\hline Desmodium adscendens (Sw.) DC. & & & & $\mathrm{X}$ & & herbácea & Magenta 90 \\
\hline D. incanum (Sw.) DC. & $X$ & & $\mathrm{X}$ & & & herbácea & Sampaio 394, Martins 749 \\
\hline Dioclea violacea Mart. ex Benth. & & $\mathrm{X}$ & $\mathrm{X}$ & & $\mathrm{X}$ & liana & Sampaio 599, 619 \\
\hline Erythrina speciosa Andrews & & $\mathrm{X}$ & $\mathrm{X}$ & & $\mathrm{O}$ & arbórea & Sampaio 335, Rossi 2057 \\
\hline Inga edulis Mart. & & & & & $\mathrm{X}$ & arbórea & Sampaio 200, 359 \\
\hline I. praegnans T.D. Penn. & & & & & $\mathrm{X}$ & arbórea & Magenta 191, Sampaio 370 \\
\hline I. sellowiana Benth. & & & $\mathrm{X}$ & & $\mathrm{X}$ & arbustiva & Sampaio 426, Martins 755 \\
\hline I. striata Benth. & & & & & $\mathrm{X}$ & arbórea & Martins 798 \\
\hline $\begin{array}{l}\text { Lonchocarpus cf. cultratus (Vell.) } \\
\text { A.M.G. Azevedo \& H.C. Lima }\end{array}$ & & & & & $\mathrm{X}$ & arbórea & Martins 514 \\
\hline Machaerium lanceolatum (Vell.) J.F. Macbr. & & & & & $\mathrm{X}$ & liana & Sampaio 379 \\
\hline M. uncinatum (Vell.) Benth. & & & $\mathrm{X}$ & & $\mathrm{X}$ & liana & Martins 769, Sampaio 737 \\
\hline Mucuna urens (L.) Medik. & & $\mathrm{X}$ & $\mathrm{X}$ & & $\mathrm{X}$ & liana & Martins 505, Sampaio 578 \\
\hline Platymiscium floribundum Vogel & & & & & $\mathrm{X}$ & arbórea & Martins 614,714 \\
\hline Pterocarpus rohrii Vahl & & & & & $\mathrm{X}$ & arbórea & Martins 800 \\
\hline $\begin{array}{l}\text { Senna pendula (Willd.) H.S. Irwin \& } \\
\text { Barneby var. glabrata (Vogel) } \\
\text { H.S. Irwin \& Barneby }\end{array}$ & & & $\mathrm{X}$ & & & arbustiva & Martins 799 \\
\hline Sophora tomentosa $\mathrm{L}$. & & $\mathrm{X}$ & & & & arbustiva & Martins 648 \\
\hline Stylosanthes viscosa $\mathrm{Sw}$. & $\mathrm{X}$ & $\mathrm{X}$ & & & & herbácea & Anunciação 681, Sampaio 546 \\
\hline Swartzia langsdorffii Raddi & & & $\mathrm{X}$ & & $\mathrm{X}$ & $\begin{array}{l}\text { arbórea / } \\
\text { arbustiva }\end{array}$ & Martins 665, 787 \\
\hline $\begin{array}{l}\text { Vigna adenantha (G. Mey.) Maréchal, } \\
\text { Mascherpa \& Stainier }\end{array}$ & & $\mathrm{X}$ & & & & liana & Sampaio 663 \\
\hline Zollernia ilicifolia (Brongn.) Vogel & & $\mathrm{X}$ & $\mathrm{X}$ & & & $\begin{array}{l}\text { arbustiva / } \\
\text { arbórea }\end{array}$ & Martins 248, Sampaio 168 \\
\hline Zornia latifolia Sm. & $\mathrm{X}$ & & & & & herbácea & Sampaio 415 \\
\hline $\begin{array}{l}\text { Zygia latifolia (L.) Fawc. \& Rendle } \\
\text { var. glabrata (Mart.) Barneby \& } \\
\text { J.W. Grimes }\end{array}$ & & & & & $\mathrm{X}$ & arbórea & Sampaio 391, 487 \\
\hline \multicolumn{8}{|l|}{ GENTIANACEAE } \\
\hline Schultesia gracilis Mart. & & & $\mathrm{X}$ & & & herbácea & Magenta 254 \\
\hline Voyria aphylla (Jacq.) Pers. & & & $\mathrm{X}$ & & & herbácea & Magenta 181 \\
\hline \multicolumn{8}{|l|}{ GESNERIACEAE } \\
\hline Besleria selloana KIotzsch \& Hanst. & & & & & $\mathrm{X}$ & herbácea & Martins 526, Magenta 200 \\
\hline Codonanthe devosiana Lem. & & & & & $\mathrm{X}$ & epífita & Magenta 125, Martins 570 \\
\hline C. gracilis (Mart.) Hanst. & & & $\mathrm{X}$ & & $\mathrm{X}$ & epífita & Martins 320, 589 \\
\hline Nematanthus fissus (Vell.) L.E. Skog & & & $\mathrm{X}$ & & $\mathrm{X}$ & epífita & Sampaio 272, Martins 354 \\
\hline N. fritschii Hoehne & & & $\mathrm{X}$ & & $\mathrm{X}$ & epífita & Sampaio 235, Martins 791 \\
\hline \multicolumn{8}{|l|}{ HELICONIACEAE } \\
\hline Heliconia angusta Vell. & & & & & $\mathrm{X}$ & herbácea & Martins 595 \\
\hline H. velloziana Emygdio & & & & & $\mathrm{X}$ & herbácea & Martins 857 \\
\hline \multicolumn{8}{|l|}{ HUMIRIACEAE } \\
\hline Humiriastrum dentatum (Casar.) Cuatrec. & & & $X$ & & & arbórea & Sampaio 183, Magenta 257 \\
\hline
\end{tabular}


Tabela 1 (continuação)

\begin{tabular}{|c|c|c|c|c|c|c|c|}
\hline \multirow[t]{2}{*}{ Família/Espécie } & \multirow[b]{2}{*}{$\begin{array}{c}\text { Praias } \\
\text { e dunas }\end{array}$} & \multicolumn{2}{|c|}{ Sobrecordões } & \multicolumn{2}{|c|}{ Depressões } & \multirow{2}{*}{$\begin{array}{c}\text { Forma } \\
\text { biológica }\end{array}$} & \multirow[t]{2}{*}{ Coletas } \\
\hline & & Escrube & Alta & $\begin{array}{c}\text { Entre } \\
\text { cordões }\end{array}$ & $\begin{array}{c}\text { Alta } \\
\text { úmida }\end{array}$ & & \\
\hline \multicolumn{8}{|l|}{ HYPOXIDACEAE } \\
\hline Hypoxis decumbens $\mathrm{L}$. & & & & & $\mathrm{X}$ & herbácea & Martins 782 \\
\hline \multicolumn{8}{|l|}{ IRIDACEAE } \\
\hline Neomarica candida (Hassl.) Sprague & & & $\mathrm{X}$ & & & herbácea & Sampaio 141 \\
\hline N. northiana (Schneev.) Sprague & & & & & $\mathrm{X}$ & herbácea & Martins 571 \\
\hline \multicolumn{8}{|l|}{ JUNCACEAE } \\
\hline Juncus acutus L. & & & & & $\mathrm{X}$ & herbácea & Martins 768 \\
\hline J. microcephalus Kunth & & & & $\mathrm{X}$ & $\mathrm{X}$ & herbácea & Sampaio 158, Martins 428 \\
\hline \multicolumn{8}{|l|}{ LAMIACEAE } \\
\hline Aegiphila fluminensis Vell. & & & $\mathrm{X}$ & & $\mathrm{X}$ & liana & Lima 27, Anunciação 668 \\
\hline A. sellowiana Cham. & & & & & $\mathrm{X}$ & arbórea & Lima 13 \\
\hline Hyptis atrorubens Poit. & & & & & $\mathrm{X}$ & herbácea & Martins 725 \\
\hline H. fasciculata Benth. subsp. fasciculata & & & & & $\mathrm{X}$ & herbácea & Sampaio 442 \\
\hline H. cf. lanceolata Poir. & & & & & $\mathrm{X}$ & herbácea & Magenta 95 \\
\hline H. lacustris A. St.-Hil. ex Benth. & & & & & $\mathrm{X}$ & herbácea & Martins 778 \\
\hline Marsypianthes chamaedrys (Vahl) Kuntze & $\mathrm{X}$ & & & & $\mathrm{X}$ & herbácea & Rossi 2023, Sampaio 413 \\
\hline Scutellaria racemosa Pers. & & & & $\mathrm{X}$ & $\mathrm{X}$ & herbácea & Martins 736 \\
\hline Vitex cf. polygama Cham. & & & & & $\mathrm{X}$ & arbórea & Sampaio 377 \\
\hline \multicolumn{8}{|l|}{ LAURACEAE } \\
\hline Aniba viridis $\mathrm{Mez}$ & & & $\mathrm{X}$ & & $\mathrm{X}$ & arbórea & Sampaio 185, Martins 792 \\
\hline Endlicheria paniculata (Spreng.) J.F. Macbr. & & & $\mathrm{X}$ & & $\mathrm{X}$ & arbórea & Martins 422, Anunciação 670 \\
\hline Nectandra grandiflora Nees \& Mart. ex Nees & & $\mathrm{X}$ & $\mathrm{X}$ & & & arbórea & Sampaio 106, Martins 720 \\
\hline N. oppositifolia Nees & & $\mathrm{X}$ & $\mathrm{X}$ & & $\mathrm{X}$ & arbórea & Magenta 226, Sampaio 548 \\
\hline$N$. cf. psammophila Nees \& Mart. ex Nees & & & & & $\mathrm{X}$ & arbórea & Martins 808 \\
\hline Ocotea aciphylla (Nees) Mez & & & $\mathrm{X}$ & & & arbórea & Sampaio 437, Magenta 224 \\
\hline O. brachybotra (Meisn.) Mez & & & $\mathrm{X}$ & & & arbórea & Sampaio 388,436 \\
\hline O. dispersa (Nees) $\mathrm{Mez}$ & & & & & $\mathrm{X}$ & arbórea & Martins 814 \\
\hline O. lanata (Nees) Mez & & & $\mathrm{X}$ & & & arbórea & Magenta 212, Sampaio 434 \\
\hline O. lobbii (Meisn.) Rohwer & & & & & $\mathrm{X}$ & arbórea & Martins 567 \\
\hline O. pulchella (Nees) Mez & & & $\mathrm{X}$ & & $\mathrm{X}$ & arbórea & Martins 446, Sampaio 230 \\
\hline O. teleiandra (Meisn.) Mez & & & $\mathrm{X}$ & & $\mathrm{X}$ & arbórea & Martins 515, Magenta 243 \\
\hline O. venulosa (Nees) Baitello & & & & & $\mathrm{X}$ & arbórea & Martins 813 \\
\hline Persea pyrifolia Nees \& Mart. ex Nees & & & $\mathrm{X}$ & & & arbórea & Martins 801 \\
\hline \multicolumn{8}{|l|}{ LENTIBULARIACEAE } \\
\hline Utricularia gibba L. & & & & $\mathrm{X}$ & & herbácea & Sampaio 142 \\
\hline U. laxa A. St.-Hil. \& Girard & & & & $\mathrm{X}$ & & herbácea & Lima 29 \\
\hline U. subulata $\mathrm{L}$. & & & & $\mathrm{X}$ & & herbácea & Martins 742, Sampaio 653 \\
\hline \multicolumn{8}{|l|}{ LOGANIACEAE } \\
\hline Spigelia beyrichiana Cham. \& Schltdl. & & & $\mathrm{X}$ & & $\mathrm{X}$ & herbácea & Sampaio 135, Martins 362 \\
\hline S. cf. schlechtendaliana Mart. & & $\mathrm{X}$ & & & $\mathrm{X}$ & herbácea & Martins 468, Magenta 133 \\
\hline \multicolumn{8}{|l|}{ LORANTHACEAE } \\
\hline Struthanthus concinnus Mart. & & & $\mathrm{X}$ & & $\mathrm{X}$ & hemiparasitc & a Sampaio 291, 574 \\
\hline \multicolumn{8}{|l|}{ MALPIGHIACEAE } \\
\hline Byrsonima intermedia A. Juss. & & & $\mathrm{X}$ & & $\mathrm{X}$ & $\begin{array}{l}\text { arbórea / } \\
\text { arbustiva }\end{array}$ & Sampaio 408, Martins 791 \\
\hline Heteropterys aenea Griseb. & & $\mathrm{X}$ & $\mathrm{X}$ & & $\mathrm{X}$ & $\begin{array}{c}\text { liana / } \\
\text { arbustiva }\end{array}$ & Martins 655, Sampaio 606 \\
\hline H. intermedia (A. Juss.) Griseb. & & $\mathrm{X}$ & & & $\mathrm{X}$ & liana & Magenta 86, Sampaio 736 \\
\hline H. nitida (Lam.) Kunth & & & & & $\mathrm{X}$ & liana & Magenta 98, Sampaio 715 \\
\hline Stigmaphyllon arenicola C.E. Anderson & $\mathrm{X}$ & $\mathrm{X}$ & $\mathrm{X}$ & & $\mathrm{X}$ & liana & Anunciação 677, Sampaio 673 \\
\hline S. ciliatum (Lam.) A. Juss. & & $\mathrm{X}$ & & & $\mathrm{X}$ & liana & Magenta 223, Sampaio 560 \\
\hline Tetrapterys acutifolia Cav. & & & & & $\mathrm{X}$ & liana & Sampaio 86, 364 \\
\hline T. chalcophylla A. Juss. & & & & & $\mathrm{X}$ & liana & Martins 575 \\
\hline T. guilleminiana A. Juss. & & & & & $\mathrm{X}$ & liana & Sampaio 729 \\
\hline T. phlomoides (Spreng.) Nied. & & & $\mathrm{X}$ & & $\mathrm{X}$ & liana & Sampaio 656, Martins 689 \\
\hline
\end{tabular}


Tabela 1 (continuação)

\begin{tabular}{|c|c|c|c|c|c|c|c|}
\hline \multirow[t]{2}{*}{ Família/Espécie } & \multirow[b]{2}{*}{$\begin{array}{l}\text { Praias } \\
\text { e dunas }\end{array}$} & \multicolumn{2}{|c|}{ Sobrecordões } & \multicolumn{2}{|c|}{ Depressões } & \multirow{2}{*}{$\begin{array}{l}\text { Forma } \\
\text { biológica }\end{array}$} & \multirow[t]{2}{*}{ Coletas } \\
\hline & & Escrube & Alta & $\begin{array}{l}\text { Entre } \\
\text { cordões }\end{array}$ & $\begin{array}{l}\text { Alta } \\
\text { úmida }\end{array}$ & & \\
\hline \multicolumn{8}{|l|}{ MALVACEAE } \\
\hline Eriotheca pentaphylla (Vell.) A. Robyns & & & $\mathrm{X}$ & & $\mathrm{X}$ & arbórea & Magenta 236, Martins 793 \\
\hline Sida sp. & & $\mathrm{X}$ & & & & herbácea & Sampaio 184 \\
\hline Sida sp. & $\mathrm{X}$ & & & & & herbácea & Martins 649 \\
\hline Triumfetta semitriloba Jacq. & & $\mathrm{X}$ & $\mathrm{X}$ & & & herbácea & Martins 467, 504 \\
\hline \multicolumn{8}{|l|}{ MARANTACEAE } \\
\hline Calathea communis Wand. \& S. Vieira & & & $\mathrm{X}$ & & $\mathrm{X}$ & herbácea & Martins 303, Sampaio 176 \\
\hline C. eichleri Petersen & & & & & $\mathrm{X}$ & herbácea & Martins 734 \\
\hline Ctenanthe lanceolata Petersen & & & $\mathrm{X}$ & & & herbácea & Sampaio 134 \\
\hline Stromanthe tonckat (Aubl.) Eichler. & & $\mathrm{X}$ & $\mathrm{X}$ & & $\mathrm{X}$ & herbácea & Sampaio 171, Martins 759 \\
\hline \multicolumn{8}{|l|}{ MARCGRAVIACEAE } \\
\hline Marcgravia polyantha Delpino & & & & & $\mathrm{X}$ & liana & Sampaio 592, Magenta 190 \\
\hline Norantea brasiliensis Choisy & & $\mathrm{X}$ & $\mathrm{X}$ & & $\mathrm{X}$ & $\begin{array}{c}\text { liana / } \\
\text { arbustiva }\end{array}$ & Martins 415, Sampaio 602 \\
\hline \multicolumn{8}{|l|}{ MELASTOMATACEAE } \\
\hline Clidemia cf. blepharodes DC. & & & $\mathrm{X}$ & & $\mathrm{X}$ & epífita & Sampaio 383, Lima 39 \\
\hline C. hirta (L.) D. Don. & & $\mathrm{X}$ & & & $\mathrm{X}$ & arbustiva & Sampaio 255, Martins 309 \\
\hline C. neglecta D. Don. & & & $\mathrm{X}$ & & $\mathrm{X}$ & arbustiva & Sampaio 380, Martins 774 \\
\hline Huberia ovalifolia DC. & & & $\mathrm{X}$ & & $\mathrm{X}$ & arbórea & Magenta 158, Sampaio 409 \\
\hline Leandra dasytricha (A. Gray) Cogn. & & & & $\mathrm{X}$ & $\mathrm{X}$ & arbustiva & Martins 307 \\
\hline L. ionopogon (Mart.) Cogn. & & & $\mathrm{X}$ & & & $\begin{array}{l}\text { arbustiva / } \\
\text { arbórea }\end{array}$ & Sampaio 146, Martins 485 \\
\hline $\begin{array}{l}\text { Miconia aff. cinerascens Miq. } \\
\text { var. robusta Wurdack }\end{array}$ & & & & & $\mathrm{X}$ & arbórea & Sampaio 452, Martins 697 \\
\hline M. cubatanensis Hoehne & & & & & $\mathrm{X}$ & arbórea & Sampaio 474 \\
\hline M. fasciculata Gardner & & & $\mathrm{X}$ & & $\mathrm{X}$ & $\begin{array}{l}\text { arbórea / } \\
\text { arbustiva }\end{array}$ & Martins 453, Sampaio 124 \\
\hline M. hymenonervia (Raddi) Cogn. & & $\mathrm{X}$ & $\mathrm{X}$ & & & arbustiva & Martins 445, Sampaio 427 \\
\hline M. prasina (Sw.) DC. & & & & & $\mathrm{X}$ & arbórea & Sampaio 300 \\
\hline M. rigidiuscula Cogn. & & & & & $\mathrm{X}$ & arbórea & Magenta 115 \\
\hline M. tristis Spring & & & $\mathrm{X}$ & & $\mathrm{X}$ & arbórea & Magenta 116, Martins 382 \\
\hline Ossaea sp. & & & $\mathrm{X}$ & & $\mathrm{X}$ & arbustiva & Martins 313, 377 \\
\hline Pterolepis glomerata (Rottb.) Miq. & & & $\mathrm{X}$ & $\mathrm{X}$ & $\mathrm{X}$ & herbácea & Sampaio 310, Magenta 205 \\
\hline Tibouchina clavata (Pers.) Wurdack & & $\mathrm{X}$ & & $\mathrm{X}$ & $\mathrm{X}$ & arbustiva & Magenta 78 \\
\hline T. pulchra Cogn. & & & $\mathrm{X}$ & & $\mathrm{X}$ & arbórea & Martins 699 Magenta 154 \\
\hline T. trichopoda (DC.) Baill. & & & $\mathrm{X}$ & & $\mathrm{X}$ & arbustiva & Sampaio 209, Magenta 126 \\
\hline T. urvilleana (DC.) Cogn. & & & & $\mathrm{X}$ & & arbustiva & Martins 783 \\
\hline \multicolumn{8}{|l|}{ MELIACEAE } \\
\hline $\begin{array}{l}\text { Cabralea canjerana (Vell.) Mart. } \\
\text { subsp. canjerana }\end{array}$ & & & & & $\mathrm{X}$ & arbórea & Sampaio 367 \\
\hline Cabralea sp. & & & $\mathrm{X}$ & & $\mathrm{X}$ & arbórea & Pastore 848, Martins 717 \\
\hline $\begin{array}{c}\text { Guarea macrophylla Vahl subsp. } \\
\text { tuberculata (Vell.) T.D. Penn. }\end{array}$ & & & & & $\mathrm{X}$ & arbórea & Sampaio 231, Martins 579 \\
\hline \multicolumn{8}{|l|}{ MENYANTHACEAE } \\
\hline Nymphoides indica (L.) Kuntze & & & & $\mathrm{X}$ & & herbácea & Lima 30 \\
\hline \multicolumn{8}{|l|}{ MONIMIACEAE } \\
\hline Mollinedia oligantha Perkins & & & & & $\mathrm{X}$ & arbórea & Sampaio 154 \\
\hline M. schottiana (Spreng.) Perkins & & & $\mathrm{X}$ & & $\mathrm{X}$ & $\begin{array}{l}\text { arbórea / } \\
\text { arbustiva }\end{array}$ & Sampaio 173, 226 \\
\hline \multicolumn{8}{|l|}{ MORACEAE } \\
\hline Dorstenia hirta Desv. & & $\mathrm{X}$ & $\mathrm{X}$ & & & herbácea & Anunciação 666, Rossi 2053 \\
\hline Ficus enormis (Mart. ex. Miq.) Miq. & & & $\mathrm{X}$ & & & arbórea & Martins 652 \\
\hline F. gomelleira Kunth \& Bouché & & & $\mathrm{X}$ & & $\mathrm{X}$ & arbórea & Martins 743 \\
\hline F. guaranitica Chodat ex Chodat \& Vischer & & & $\mathrm{X}$ & & $\mathrm{X}$ & arbórea & Martins 497 \\
\hline F. insipida Willd. & & & & & $\mathrm{X}$ & arbórea & Martins 440 \\
\hline
\end{tabular}


Tabela 1 (continuação)

\begin{tabular}{|c|c|c|c|c|c|c|c|}
\hline \multirow[t]{2}{*}{ Família/Espécie } & \multirow[b]{2}{*}{$\begin{array}{c}\text { Praias } \\
\text { e dunas }\end{array}$} & \multicolumn{2}{|c|}{ Sobrecordões } & \multicolumn{2}{|c|}{ Depressões } & \multirow{2}{*}{$\begin{array}{c}\text { Forma } \\
\text { biológica }\end{array}$} & \multirow[t]{2}{*}{ Coletas } \\
\hline & & Escrube & Alta & $\begin{array}{c}\text { Entre } \\
\text { cordões }\end{array}$ & $\begin{array}{c}\text { Alta } \\
\text { úmida }\end{array}$ & & \\
\hline Ficus luschnathiana (Miq.) Miq. & & & & & $\mathrm{X}$ & arbórea & Martins 413, Lima 06 \\
\hline $\begin{array}{l}\text { Sorocea racemosa Gaudich. subsp. } \\
\text { grandifolia } \text { Romaniuc-Neto }\end{array}$ & & & $\mathrm{X}$ & & & arbórea & Martins 500 \\
\hline \multicolumn{8}{|l|}{ MYRSINACEAE } \\
\hline Ardisia martiana Miq. & & & & & $\mathrm{X}$ & arbórea & Lima 24, Sampaio 528 \\
\hline Cybianthus peruvianus (A. DC.) Miq. & & & $\mathrm{X}$ & & $\mathrm{X}$ & arbórea & Martins 558, Pastore 847 \\
\hline Rapanea ferruginea (Ruiz \& Pav.) Mez & & $X$ & $\mathrm{X}$ & $\mathrm{X}$ & $\mathrm{X}$ & arbórea & Sampaio 360, Martins 508 \\
\hline R. guianensis Aubl. & & $\mathrm{X}$ & & & & arbórea & Sampaio 307 \\
\hline $\begin{array}{l}\text { R. hermogenesii Jung-Mendaçolli } \\
\text { \& Bernacci }\end{array}$ & & & & & $\mathrm{X}$ & arbórea & Martins 797 \\
\hline R. parvifolia (A. DC.) Mez & & $\mathrm{X}$ & & & & arbórea & Martins 724 \\
\hline R. venosa (A. DC.) Mez & & $\mathrm{X}$ & $\mathrm{X}$ & & $\mathrm{X}$ & arbórea & Sampaio 747, Martins 496 \\
\hline \multicolumn{8}{|l|}{ MYRTACEAE } \\
\hline Blepharocalyx salicifolius (Kunth) O. Berg & & & $\mathrm{X}$ & & & $\begin{array}{l}\text { arbustiva / } \\
\text { arbórea }\end{array}$ & Martins 441, 788 \\
\hline Calycorectes acutatus (Miq.) Toledo & & & & & $\mathrm{X}$ & arbórea & Sampaio 790 \\
\hline cf. Calycorectes australis D. Legrand & & & & & $\mathrm{X}$ & arbórea & Sampaio 791 \\
\hline Calyptranthes concinna DC. & & & $\mathrm{X}$ & & $\mathrm{X}$ & $\begin{array}{l}\text { arbórea / } \\
\text { arbustiva }\end{array}$ & Martins 796, Sampaio 447 \\
\hline C. lucida Mart. ex DC. & & & & & $\mathrm{X}$ & arbórea & Sampaio 792 \\
\hline Campomanesia guaviroba (DC.) Kiaersk. & & & $\mathrm{X}$ & & $\mathrm{X}$ & arbórea & Martins 408, 409 \\
\hline Eugenia cf. capitulifera O. Berg & & & $\mathrm{X}$ & & $\mathrm{X}$ & arbórea & Sampaio 793 \\
\hline E. copacabanensis Kiaersk. & & & $\mathrm{X}$ & & $\mathrm{X}$ & arbórea & Martins 318 \\
\hline E. crassiflora Kiaersk. & & & & & $\mathrm{X}$ & arbórea & Martins 460, 549 \\
\hline E. disperma Vell. & & & & & $\mathrm{X}$ & arbórea & Sampaio 794 \\
\hline $\begin{array}{l}\text { E. cf. melanogyna (D. Legrand) } \\
\text { Sobral }\end{array}$ & & & & & $\mathrm{X}$ & arbórea & Martins 615 \\
\hline E. monosperma Vell. & & & & & $\mathrm{X}$ & arbórea & Martins 281, 397 \\
\hline E. neolanceolata Sobral & & & $\mathrm{X}$ & & $\mathrm{X}$ & arbórea & Martins 718, Sampaio 448 \\
\hline E. oblongata O.Berg & & & $\mathrm{X}$ & & $\mathrm{X}$ & arbórea & Sampaio 347 \\
\hline E. riedeliana $\mathrm{O}$. Berg & & & $X$ & & $\mathrm{X}$ & arbórea & Sampaio 211, 471 \\
\hline E. speciosa Cambess. & & $\mathrm{X}$ & $\mathrm{X}$ & & & $\begin{array}{l}\text { arbórea / } \\
\text { arbustiva }\end{array}$ & Sampaio 352, Martins 738 \\
\hline E. stigmatosa DC. & & & $X$ & & $\mathrm{X}$ & arbórea & Magenta 218, Martins 746 \\
\hline E. subavenia O. Berg & & & & & $\mathrm{X}$ & arbórea & Sampaio 537 \\
\hline E. sulcata Spring & & & $\mathrm{X}$ & & $\mathrm{X}$ & arbórea & Lima 04, Pastore 846 \\
\hline E. tinguyensis Cambess. & & & $\mathrm{X}$ & & & arbórea & Magenta 210 \\
\hline E. umbelliflora O. Berg & & $\mathrm{X}$ & $\mathrm{X}$ & & & $\begin{array}{l}\text { arbórea / } \\
\text { arbustiva }\end{array}$ & Sampaio 545, Martins 739 \\
\hline E. velutiflora Kiaersk. & & & $X$ & & & arbórea & Magenta 174, Lima 36 \\
\hline Eugenia sp. & & & & & $X$ & arbórea & Sampaio 541 \\
\hline Gomidesia fenzliana $\mathrm{O}$. Berg & & & $\mathrm{X}$ & & & arbórea & Magenta 155, Sampaio 308 \\
\hline G. shaueriana O. Berg & & & & & $\mathrm{X}$ & arbórea & Sampaio 317, Martins 761 \\
\hline Marlierea obscura O. Berg & & & & & $\mathrm{X}$ & arbórea & Magenta 117, Sampaio 290 \\
\hline M. cf. parviflora O. Berg & & & & & $\mathrm{X}$ & arbórea & Martins 482 \\
\hline M. racemosa (Vell.) Kiaersk. & & $\mathrm{X}$ & $\mathrm{X}$ & & $\mathrm{X}$ & arbórea & Anunciação 679, Rossi 2056 \\
\hline M. tomentosa Cambess. & & & & & $\mathrm{X}$ & arbórea & Sampaio 366, Magenta 199 \\
\hline $\begin{array}{l}\text { Myrceugenia campestris (DC.) D. } \\
\text { Legrand \& Kaus. }\end{array}$ & & & & & $\mathrm{X}$ & arbórea & Sampaio 795 \\
\hline Myrcia acuminatissima $\mathrm{O}$. Berg & & & $\mathrm{X}$ & & $\mathrm{X}$ & arbórea & Sampaio 271, Magenta 197 \\
\hline M. fallax (Rich.) DC. & & $\mathrm{X}$ & $\mathrm{X}$ & & $\mathrm{X}$ & arbórea & Martins 246, Sampaio 353 \\
\hline M. grandiflora (O. Berg.) Nied. & & & & & $\mathrm{X}$ & arbórea & Sampaio 83,375 \\
\hline M. macrocarpa DC. & & & & & $\mathrm{X}$ & $\begin{array}{l}\text { arbórea / } \\
\text { arbustiva }\end{array}$ & Sampaio 382, Martins 765 \\
\hline M. multiflora (Lam.) DC. & & & $X$ & & $X$ & $\begin{array}{l}\text { arbórea / } \\
\text { arbustiva }\end{array}$ & Lima 35, Sampaio 573 \\
\hline
\end{tabular}


Tabela 1 (continuação)

\begin{tabular}{|c|c|c|c|c|c|c|c|}
\hline \multirow[t]{2}{*}{ Família/Espécie } & \multirow[b]{2}{*}{$\begin{array}{l}\text { Praias } \\
\text { e dunas }\end{array}$} & \multicolumn{2}{|c|}{ Sobrecordões } & \multicolumn{2}{|c|}{ Depressões } & \multirow{2}{*}{$\begin{array}{l}\text { Forma } \\
\text { biológica }\end{array}$} & \multirow[t]{2}{*}{ Coletas } \\
\hline & & Escrube & Alta & $\begin{array}{l}\text { Entre } \\
\text { cordões }\end{array}$ & $\begin{array}{l}\text { Alta } \\
\text { úmida }\end{array}$ & & \\
\hline Myrcia palustris DC. & & & $\mathrm{X}$ & $\mathrm{X}$ & & $\begin{array}{l}\text { arbórea / } \\
\text { arbustiva }\end{array}$ & Martins 654, Sampaio 428 \\
\hline M. pubipetala Miq. & & & $\mathrm{X}$ & & $\mathrm{X}$ & arbórea & Sampaio 449, Martins 663 \\
\hline Plinia cf. rivularis (Cambess.) A.D. Rotman & & & & & $\mathrm{X}$ & arbórea & Martins 729 \\
\hline Psidium cattleyanum Sabine & & $\mathrm{X}$ & $\mathrm{X}$ & & $\mathrm{X}$ & $\begin{array}{l}\text { arbórea / } \\
\text { arbustiva }\end{array}$ & Sampaio 406, 422 \\
\hline \multicolumn{8}{|l|}{ NYCTAGINACEAE } \\
\hline Guapira nitida (Mart. ex Schmidt) Lundell & & & $\mathrm{X}$ & & $\mathrm{X}$ & arbórea & Sampaio 357, Martins 605 \\
\hline G. opposita (Vell.) Reitz & & $\mathrm{X}$ & $\mathrm{X}$ & & $\mathrm{X}$ & $\begin{array}{l}\text { arbórea / } \\
\text { arbustiva }\end{array}$ & Magenta 240, Anunciação 663 \\
\hline \multicolumn{8}{|l|}{ OCHNACEAE } \\
\hline Ouratea parviflora (DC.) Baill. & & & $\mathrm{X}$ & & & $\begin{array}{l}\text { arbustiva / } \\
\text { arbórea }\end{array}$ & Martins 367, 432 \\
\hline Sauvagesia erecta $\mathrm{L}$. & & $\mathrm{X}$ & & $\mathrm{X}$ & $\mathrm{X}$ & herbácea & Martins 338, 374 \\
\hline OLACACEAE & & & & & & & \\
\hline Heisteria silvianii Schwacke & & & $\mathrm{X}$ & & $\mathrm{X}$ & arbórea & Magenta 209 \\
\hline ONAGRACEAE & & & & & & & \\
\hline Ludwigia octovalvis (Jacq.) P.H. Raven & & & & $\mathrm{X}$ & $\mathrm{X}$ & herbácea & Magenta 136, Sampaio 655 \\
\hline \multicolumn{8}{|l|}{ ORCHIDACEAE } \\
\hline Aspidogyne argentea (Vell.) Garay & & & & & $\mathrm{X}$ & herbácea & Martins 590, 576 \\
\hline Aspidogyne sp. & & & & & $\mathrm{X}$ & herbácea & Sampaio 542 \\
\hline $\begin{array}{l}\text { Campylocentrum micranthum } \\
\text { (Lindl.) Rolfe }\end{array}$ & & & & & $\mathrm{X}$ & epífita & Sampaio 205, 536 \\
\hline C. aff. micranthum (Lindl.) Rolfe & & & & & $\mathrm{X}$ & epífita & Martins 752 \\
\hline Cattleya intermedia Graham & & & $\mathrm{X}$ & & $\mathrm{X}$ & epífita & Sampaio 354, 557 \\
\hline Cyclopogon sp. & & & $\mathrm{X}$ & & & $\begin{array}{l}\text { herbácea / } \\
\text { epífita }\end{array}$ & Sampaio 350, Rossi 2054 \\
\hline $\begin{array}{l}\text { Cyrtopodium polyphyllum (Vell.) } \\
\text { Pabst ex F. Barros }\end{array}$ & & & $\mathrm{X}$ & & & herbácea & Martins 347, Sampaio 389 \\
\hline Dichaea cf. pendula (Aubl.) Cogn. & & & $\mathrm{X}$ & & & epífita & Martins 591 \\
\hline Elleanthus brasiliensis Rchb. f. & & & $\mathrm{X}$ & & $\mathrm{X}$ & epífita & Lima 31 \\
\hline Epidendrum avicula Lindl. & & & $\mathrm{X}$ & & & epífita & Sampaio 251 \\
\hline E. cristatum Ruiz \& Pav. & & & & & $\mathrm{X}$ & epífita & Martins 457 \\
\hline E. denticulatum Barb. Rodr. & & & & & $\mathrm{X}$ & herbácea & Sampaio 562 \\
\hline E. fulgens Brongn. & & $\mathrm{X}$ & & & & herbácea & Martins 382 \\
\hline E. latilabre Lindl. & & & & & $\mathrm{X}$ & epífita & Sampaio 196 \\
\hline E. rigidum Jacq. & & & $\mathrm{X}$ & & & epífita & Sampaio 250 \\
\hline E. secundum Jacq. & & & $\mathrm{X}$ & & & herbácea & Martins 341 \\
\hline Habenaria parviflora Lindl. & & & & & $\mathrm{X}$ & herbácea & Martins 700 \\
\hline Huntleya meleagris Lindl. & & & $\mathrm{X}$ & & & epífita & Martins 737 \\
\hline Lockhartia lunifera (Lindl.) Rchb. f. & & & $\mathrm{X}$ & & & epífita & Sampaio 249 \\
\hline Maxillaria brasiliensis Brieger \& Illg & & & $\mathrm{X}$ & & & epífita & Martins 683 \\
\hline M. notylioglossa Rchb. f. & & & & & $\mathrm{X}$ & epífita & Martins 694 \\
\hline M. pachyphylla Schltr. ex Hoehne & & & & & $\mathrm{X}$ & epífita & Lima 20 \\
\hline Mesadenella cf. cuspidata (Lindl.) Garay & & & $\mathrm{X}$ & & & herbácea & Martins 661, 686 \\
\hline Octomeria bradei Schltr. & & & $\mathrm{X}$ & & & epífita & Sampaio 390 \\
\hline O. grandiflora Lindl. & & & & & $\mathrm{X}$ & epífita & Martins 324 \\
\hline O. cf. grandiflora Lindl. & & & $\mathrm{X}$ & & & epífita & Martins 730 \\
\hline Oeceoclades maculata (Lindl.) Lindl. & & & & & $\mathrm{X}$ & herbácea & Martins 692, Sampaio 451 \\
\hline Oncidium flexuosum Sims & & & & & $\mathrm{X}$ & epífita & Magenta 231 \\
\hline Pleurothallis aff. auriculata Lindl. & & & & & $\mathrm{X}$ & epífita & Martins 670 \\
\hline P. deregularis (Barb. Rodr.) Luer & & & & & $\mathrm{X}$ & epífita & Sampaio 530 \\
\hline$P$. aff. graveolens Pabst & & & & & $\mathrm{X}$ & epífita & Sampaio 128 \\
\hline P. grobyi Lindl. & & & & & $\mathrm{X}$ & epífita & Sampaio 228, 229 \\
\hline P. linearifolia Cogn. & & & $\mathrm{X}$ & & & epífita & Sampaio 244 \\
\hline
\end{tabular}


Tabela 1 (continuação)

\begin{tabular}{|c|c|c|c|c|c|c|c|}
\hline \multirow[t]{2}{*}{ Família/Espécie } & \multirow[b]{2}{*}{$\begin{array}{l}\text { Praias } \\
\text { e dunas }\end{array}$} & \multicolumn{2}{|c|}{ Sobrecordões } & \multicolumn{2}{|c|}{ Depressões } & \multirow{2}{*}{$\begin{array}{c}\text { Forma } \\
\text { biológica }\end{array}$} & \multirow[t]{2}{*}{ Coletas } \\
\hline & & Escrube & Alta & $\begin{array}{c}\text { Entre } \\
\text { cordões }\end{array}$ & $\begin{array}{c}\text { Alta } \\
\text { úmida }\end{array}$ & & \\
\hline Pleurothallis cf. malmeana Dutra ex Pabst & & & $\mathrm{X}$ & & & epífita & Martins 323 \\
\hline P. quadridentata (Barb. Rodr.) Cogn. & & & $\mathrm{X}$ & & & epífita & Martins 593 \\
\hline Pleurothallis sp. 1 & & & & & $\mathrm{X}$ & epífita & Martins 758 \\
\hline Pleurothallis sp. 2 & & & $\mathrm{X}$ & & & epífita & Sampaio 252 \\
\hline Polystachya estrellensis Rchb. f. & & & & & $\mathrm{X}$ & epífita & Sampaio 376 \\
\hline Prescottia densiflora Lindl. & & & $\mathrm{X}$ & & $\mathrm{X}$ & herbácea & Sampaio 535, Martins 766 \\
\hline P. stachyodes (Sw.) Lindl. & & & $\mathrm{X}$ & & & herbácea & Martins 431 \\
\hline Prosthechea fragans (Sw.) W.E. Higgins & & & $X$ & & $\mathrm{X}$ & epífita & Sampaio 227, Martins 798 \\
\hline P. vespa (Vell.) W.E. Higgins & & & & & $\mathrm{X}$ & epífita & Lima 23 \\
\hline Rodriguezia venusta Rchb. f. & & & & & $\mathrm{X}$ & epífita & Sampaio 125 \\
\hline Stelis sp. 1 & & & $X$ & & & epífita & Lima 41 \\
\hline Stelis sp. 2 & & & & & $\mathrm{X}$ & epífita & Lima 19 \\
\hline Vanilla parvifolia Barb. Rodr. & & & $\mathrm{X}$ & & & liana & Martins 348, 489 \\
\hline Zootrophion schenckii (Cogn.) Luer & & & $\mathrm{X}$ & & & epífita & Sampaio 243 \\
\hline \multicolumn{8}{|l|}{ PASSIFLORACEAE } \\
\hline Passiflora edulis Sims & & $\mathrm{X}$ & $\mathrm{X}$ & & & liana & Martins 481, Sampaio 633 \\
\hline P. jilekii Wawra & & $\mathrm{X}$ & $\mathrm{X}$ & & $\mathrm{X}$ & liana & Sampaio 600, Martins 651 \\
\hline P. organensis Gardner & & & $X$ & & $\mathrm{X}$ & liana & Sampaio 731,733 \\
\hline \multicolumn{8}{|l|}{ PENTAPHYLLACACEAE } \\
\hline Ternstroemia brasiliensis Cambess. & & $\mathrm{X}$ & $\mathrm{X}$ & & $\mathrm{X}$ & $\begin{array}{l}\text { arbustiva / } \\
\text { arbórea }\end{array}$ & Anunciação 683, Sampaio 424 \\
\hline \multicolumn{8}{|l|}{ PHYLLANTHACEAE } \\
\hline Phyllanthus niruri L. & & & & & $\mathrm{X}$ & herbácea & Martins 701 \\
\hline Richeria grandis Vahl & & & & & $\mathrm{X}$ & arbórea & Martins 799 \\
\hline \multicolumn{8}{|l|}{ PHYTOLACCACEAE } \\
\hline Phytolacca thyrsiflora Fenzl ex J.A. Schmidt & & & $\mathrm{X}$ & & & herbácea & Magenta 219 \\
\hline \multicolumn{8}{|l|}{ PICRAMNIACEAE } \\
\hline Picramnia gardneri Planch. & & & & & $\mathrm{X}$ & $\begin{array}{l}\text { arbórea / } \\
\text { arbustiva }\end{array}$ & Magenta 227, Sampaio 644 \\
\hline \multicolumn{8}{|l|}{ PIPERACEAE } \\
\hline Peperomia corcovadensis Gardner & & $\mathrm{X}$ & $X$ & & & epífita & Sampaio 119, Anunciação 667 \\
\hline P. glabella (Sw.) A. Dietr. & & & $\mathrm{X}$ & & $\mathrm{X}$ & epífita & Rossi 2016, Lima 34 \\
\hline P. obtusifolia (L.) A. Dietr. & & & $\mathrm{X}$ & & & epífita & Sampaio 239, 245 \\
\hline P. rotundifolia $($ L.) Kunth & & & $\mathrm{X}$ & & $\mathrm{X}$ & epífita & Martins 321 \\
\hline Piper arboreum Aubl. & & & $X$ & & & arbustiva & Martins 492, Magenta 256 \\
\hline P. caldense C. DC. & & & $\mathrm{X}$ & & & arbustiva & Lima 47 \\
\hline P. cernuum Vell. & & & & & $\mathrm{X}$ & arbustiva & Sampaio 95, Martins 358 \\
\hline P. gaudichaudianum Kunth & & & $\mathrm{X}$ & & $\mathrm{X}$ & arbustiva & Sampaio 182, Martins 300 \\
\hline P. solmsianum C. DC. & & & & & $\mathrm{X}$ & arbustiva & Martins 733 \\
\hline \multicolumn{8}{|l|}{ PLANTAGINACEAE } \\
\hline Achetaria ocymoides (Cham. \& Schltdl.) Wetts & tst. & $\mathrm{X}$ & $\mathrm{X}$ & & $\mathrm{X}$ & herbácea & Sampaio 482, 483 \\
\hline Bacopa monnieri (L.) Wettst. & $\mathrm{X}$ & & & & & herbácea & Martins 640 \\
\hline Lindernia crustacea (L.) F. Muell. & & & $X$ & & & herbácea & Sampaio 333 \\
\hline L. diffusa (L.) Wettst. & & & & $\mathrm{X}$ & $\mathrm{X}$ & herbácea & Martins 330, Sampaio 210 \\
\hline Plantago catharinea Decne. & $\mathrm{X}$ & & & & & herbácea & Sampaio 416 \\
\hline Stemodia vandellioides (Benth.) V.C. Souza & & & & & $\mathrm{X}$ & herbácea & Sampaio 212 \\
\hline \multicolumn{8}{|l|}{ POACEAE } \\
\hline Andropogon bicornis $\mathrm{L}$. & & & & $\mathrm{X}$ & & herbácea & Lima 40 \\
\hline Cenchrus echinatus L. & $\mathrm{X}$ & & & & & herbácea & Martins 644 \\
\hline Chloris retusa Lag. & $\mathrm{X}$ & & & & & herbácea & Sampaio 420 \\
\hline Cryptochloa capillata (Trin.) Soderstr. & & & $\mathrm{X}$ & & & herbácea & Martins 369 \\
\hline Eragrostis bahiensis Schult. & $\mathrm{X}$ & & & & & herbácea & Martins 748 \\
\hline E. mexicana (Hornem.) Link. & & & & & $\mathrm{X}$ & herbácea & Martins 771 \\
\hline Ichnanthus pallens (Sw.) Munro & & & & & $\mathrm{X}$ & herbácea & Martins 709 \\
\hline
\end{tabular}


Tabela 1 (continuação)

\begin{tabular}{|c|c|c|c|c|c|c|c|}
\hline \multirow[t]{2}{*}{ Família/Espécie } & \multirow[b]{2}{*}{$\begin{array}{l}\text { Praias } \\
\text { e dunas }\end{array}$} & \multicolumn{2}{|c|}{ Sobrecordões } & \multicolumn{2}{|c|}{ Depressões } & \multirow{2}{*}{$\begin{array}{c}\text { Forma } \\
\text { biológica }\end{array}$} & \multirow[t]{2}{*}{ Coletas } \\
\hline & & Escrube & Alta & $\begin{array}{l}\text { Entre } \\
\text { cordões }\end{array}$ & $\begin{array}{l}\text { Alta } \\
\text { úmida }\end{array}$ & & \\
\hline $\begin{array}{l}\text { Ichnanthus pallens (Sw.) Munro } \\
\text { ex Benth. var. pallens }\end{array}$ & & & & & $\mathrm{X}$ & herbácea & Sampaio 201 \\
\hline Ischaemum minus J. Presl. & & & & & $\mathrm{X}$ & herbácea & Sampaio 553 \\
\hline Lasiacis ligulata Hitchc. \& Chase & & & $\mathrm{X}$ & & & herbácea & Sampaio 264, Martins 685 \\
\hline Merostachys sp. & & & $\mathrm{X}$ & & & liana & Sampaio 601 \\
\hline Panicum stoloniferum Poir. & & & & & $\mathrm{X}$ & herbácea & Sampaio 207 \\
\hline Paspalum corcovadense Raddi & & & $X$ & & & herbácea & Sampaio 469 \\
\hline P. densum Poir. & & $\mathrm{X}$ & & & & herbácea & Martins 462 \\
\hline P. maritimum Trin. & & $\mathrm{X}$ & & & $\mathrm{X}$ & herbácea & Sampaio 262, Martins 776 \\
\hline P. vaginatum $\mathrm{Sw}$. & & & & & $\mathrm{X}$ & herbácea & Martins 770 \\
\hline Saccharum villosum Steud. & & & $\mathrm{X}$ & & & herbácea & Sampaio 551 \\
\hline Setaria poiretiana (Schult.) Kunth & & $\mathrm{X}$ & & & & herbácea & Sampaio 280 \\
\hline Sporobolus virginicus (L.) Kunth & $\mathrm{X}$ & & & & & herbácea & Sampaio 637 \\
\hline $\begin{array}{l}\text { Stenotaphrum secundatum (Walter) } \\
\text { O. Kuntze }\end{array}$ & $X$ & & & & & herbácea & Martins 645 \\
\hline PODOCARPACEAE & & & & & & & \\
\hline Podocarpus sellowii Klotzsch ex Endl. & & & $\mathrm{X}$ & & $\mathrm{X}$ & arbórea & Sampaio 112 \\
\hline POLYGALACEAE & & & & & & & \\
\hline Polygala cyparissias A. St.-Hil. \& Moq. & $\mathrm{X}$ & & & & & herbácea & Martins 385 \\
\hline P. paniculata $\mathrm{L}$ & & & & $\mathrm{X}$ & & herbácea & Magenta 188 \\
\hline Securidaca cf. macrocarpa A.W. Benn. & & & & $\mathrm{X}$ & & liana & Martins 792 \\
\hline POLYGONACEAE & & & & & & & \\
\hline Coccoloba fastigiata Meisn. & & & $\mathrm{X}$ & & $\mathrm{X}$ & arbórea & Martins 639 \\
\hline C. mosenii Lindl. & & & $\mathrm{X}$ & & $\mathrm{X}$ & liana & Sampaio 587, 627 \\
\hline Polygonum meisnerianum Cham. \& Schltdl. & & & & & $\mathrm{X}$ & herbácea & Martins 414 \\
\hline PORTULACACEAE & & & & & & & \\
\hline Portulaca striata Poelln. & $\mathrm{X}$ & & & & & herbácea & Magenta 222 \\
\hline PROTEACEAE & & & & & & & \\
\hline Roupala paulensis Sleumer & & & $\mathrm{X}$ & & & arbórea & Sampaio 425 \\
\hline RHAMNACEAE & & & & & & & \\
\hline Rhamnus sphaerosperma $\mathrm{Sw}$. & & & $\mathrm{X}$ & & $\mathrm{X}$ & arbórea & Pastore 845, Martins 603 \\
\hline ROSACEAE & & & & & & & \\
\hline Prunus myrtifolia (L.) Urb. & & & & & $\mathrm{X}$ & arbórea & Magenta 91, 135 \\
\hline RUBIACEAE & & & & & & & \\
\hline Alibertia aff. myrciifolia $\mathrm{K}$. Schum. & & & & & $\mathrm{X}$ & arbustiva & Martins 419, Sampaio 445 \\
\hline Amaioua intermedia Mart. & & & $\mathrm{X}$ & & $\mathrm{X}$ & arbórea & Anunciação 671, Sampaio 190 \\
\hline $\begin{array}{l}\text { Borreria ocymifolia (Willd. ex Roem. \& } \\
\text { Schult.) Bacigalupo \& E.L. Cabral }\end{array}$ & & & & & $X$ & herbácea & Martins 423, Sampaio 203 \\
\hline B. oligodonta Steyerm & & $\mathrm{X}$ & & & $\mathrm{X}$ & herbácea & Martins 478, 863 \\
\hline Chiococca alba (L.) Hitchc. & & $\mathrm{X}$ & & & $X$ & liana & Magenta 183, Sampaio 604 \\
\hline $\begin{array}{l}\text { Coccocypselum capitatum (Graham) } \\
\text { C.B. Costa \& Mamede }\end{array}$ & & & & & $\mathrm{X}$ & herbácea & Martins 232 \\
\hline C. condalia Pers. & & & $\mathrm{X}$ & & & herbácea & Sampaio 143 \\
\hline C. cordifolium Nees \& Mart. & & & $\mathrm{X}$ & & & herbácea & Anunciação 675 \\
\hline $\begin{array}{l}\text { Diodella apiculata (Willd. ex Roem. \& } \\
\text { Schult.) Bacigalupo \& E.L. Cabral }\end{array}$ & & & $X$ & & & herbácea & Magenta 151, Martins 744 \\
\hline $\begin{array}{l}\text { D. radula (Willd. \& Hoffmanns. ex } \\
\text { Roem. \& Schult.) Bacigalupo \& } \\
\text { E.L. Cabral }\end{array}$ & $\mathrm{X}$ & $\mathrm{X}$ & & $\mathrm{X}$ & & herbácea & Magenta 153, Sampaio 118 \\
\hline Emmeorhiza umbellata (Spreng.) K. Schum. & & & $\mathrm{X}$ & & $\mathrm{X}$ & liana & Magenta 157, Martins 493 \\
\hline $\begin{array}{l}\text { Faramea multiflora A. Rich. var. salicifolia } \\
\text { (C. Presl) Steyerm. }\end{array}$ & & & & & $\mathrm{X}$ & arbustiva & Martins 811 \\
\hline Geophila repens (L.) I.M. Johns. & & & $\mathrm{X}$ & & $\mathrm{X}$ & herbácea & Sampaio 198, Martins 486 \\
\hline Hillia cf. illustris (Vell.) K. Schum. & & & & & $\mathrm{X}$ & arbustiva & Sampaio 156 \\
\hline H. parasitica Jacq. & & & & & $\mathrm{X}$ & liana & Sampaio 160 \\
\hline
\end{tabular}


Tabela 1 (continuação)

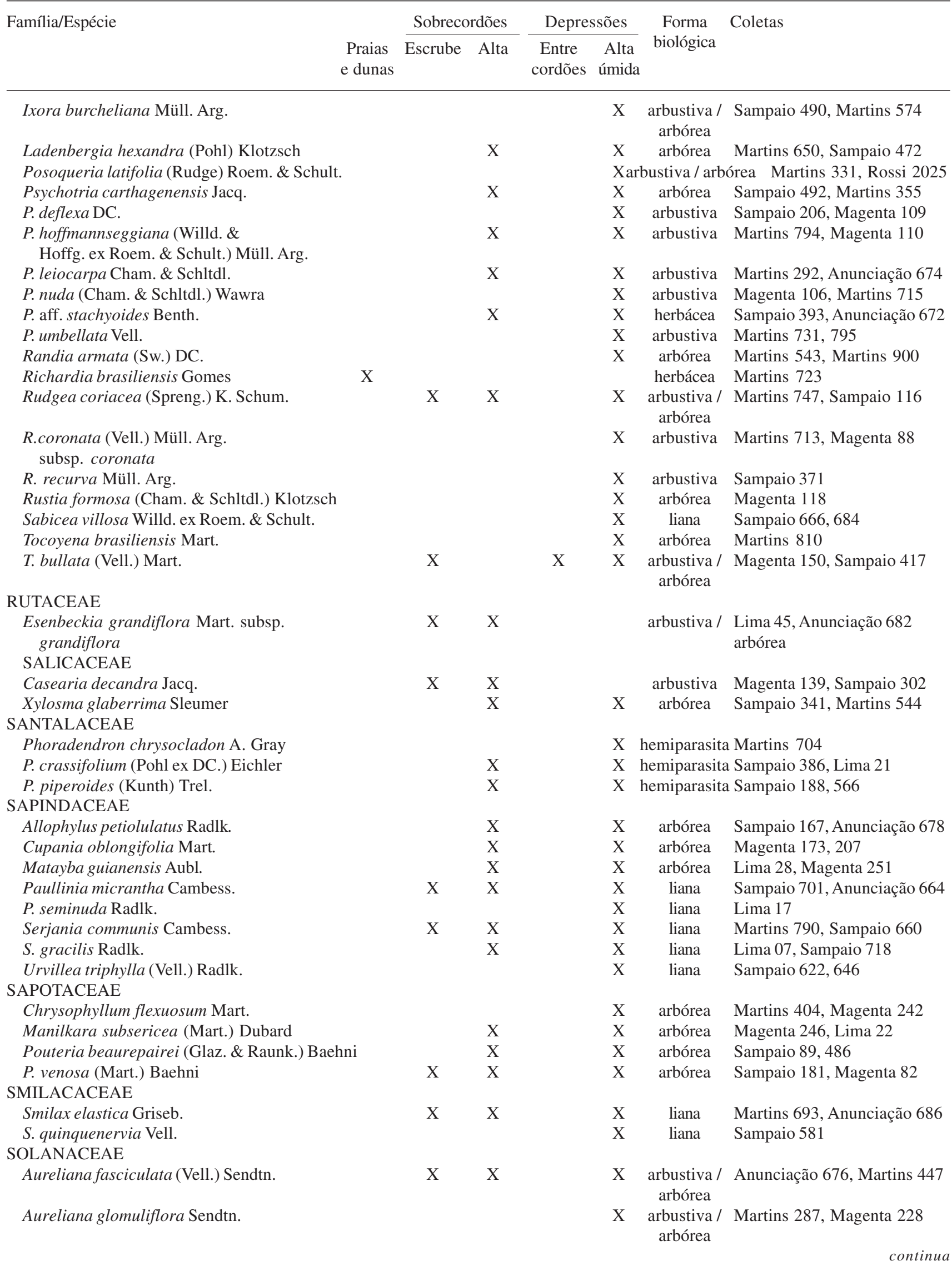


Tabela 1 (continuação)

\begin{tabular}{|c|c|c|c|c|c|c|c|}
\hline \multirow[t]{2}{*}{ Família/Espécie } & \multirow[b]{2}{*}{$\begin{array}{c}\text { Praias } \\
\text { e dunas }\end{array}$} & \multicolumn{2}{|c|}{ Sobrecordões } & \multicolumn{2}{|c|}{ Depressões } & \multirow{2}{*}{$\begin{array}{c}\text { Forma } \\
\text { biológica }\end{array}$} & \multirow[t]{2}{*}{ Coletas } \\
\hline & & Escrube & Alta & $\begin{array}{l}\text { Entre } \\
\text { cordões }\end{array}$ & $\begin{array}{l}\text { Alta } \\
\text { úmida }\end{array}$ & & \\
\hline Cestrum laevigatum Schltdl. & & & $\mathrm{X}$ & & & arbustiva & Martins 795 \\
\hline C. schlechtendalii G. Don & & & $\mathrm{X}$ & & & arbórea & Martins 796 \\
\hline Dyssochroma viridiflora (Sims.) Miers & & & & & $\mathrm{X}$ & $\begin{array}{l}\text { arbustiva / } \\
\text { arbórea }\end{array}$ & Magenta 195 \\
\hline Physalis cf. angulata $\mathrm{L}$. & & & & & $\mathrm{X}$ & herbácea & Martins 789 \\
\hline Solanum americanum Mill. & & & $\mathrm{X}$ & & & herbácea & Martins 555 \\
\hline S. atropurpureum Schrank & & & & & $\mathrm{X}$ & herbácea & Martins 364 \\
\hline S. capsicoides All. & & & $\mathrm{X}$ & & & herbácea & Sampaio 186 \\
\hline S. castaneum Carvalho & & & & & $\mathrm{X}$ & arbórea & Martins 548 \\
\hline S. mauritianum Scop. & & & & & $\mathrm{X}$ & arbustiva & Martins 705 \\
\hline S. pseudoquina A. St.-Hil. & & & $\mathrm{X}$ & & & arbórea & Sampaio 544, Martins 794 \\
\hline S. stipulatum Vell. & & & $\mathrm{X}$ & & $\mathrm{X}$ & arbustiva & Lima 37, Sampaio 540 \\
\hline S. torvum Sw. & & & $\mathrm{X}$ & & $\mathrm{X}$ & arbustiva & Sampaio 197, Magenta 123 \\
\hline S. wacketii Witasek & & & & & $\mathrm{X}$ & arbustiva & Martins 781 \\
\hline \multicolumn{8}{|l|}{ STYRACACEAE } \\
\hline Styrax glaber Sw. & & & $\mathrm{X}$ & & & arbórea & Martins 600, Lima 46 \\
\hline \multicolumn{8}{|l|}{ THEACEAE } \\
\hline Gordonia fruticosa (Schrad.) H. Keng & & & & & $\mathrm{X}$ & $\begin{array}{l}\text { arbórea / } \\
\text { arbustiva }\end{array}$ & Sampaio 361 \\
\hline \multicolumn{8}{|l|}{ THYMELAEACEAE } \\
\hline Daphnopsis racemosa Griseb. & & & $\mathrm{X}$ & & $\mathrm{X}$ & $\begin{array}{l}\text { arbórea / } \\
\text { arbustiva }\end{array}$ & Martins 560, Sampaio 378 \\
\hline \multicolumn{8}{|l|}{ URTICACEAE } \\
\hline Boehmeria caudata Sw. & & & & & $\mathrm{X}$ & arbustiva & Martins 566 \\
\hline B. cylindrica (L.) Sw. & & & & & $\mathrm{X}$ & arbustiva & Rossi 2019 \\
\hline Cecropia glazioui Snethl. & & & $\mathrm{X}$ & & $\mathrm{X}$ & arbórea & Martins 314 \\
\hline C. pachystachya Trécul & & & & & $\mathrm{X}$ & arbórea & Magenta 248 \\
\hline Coussapoa microcarpa (Schott) Rizzini & & & $\mathrm{X}$ & & $\mathrm{X}$ & $\begin{array}{c}\text { arbórea/ } \\
\text { hemiepífita }\end{array}$ & Martins 634, Sampaio 532 \\
\hline Phenax sonneratii (Poir.) Wedd. & & & & & $\mathrm{X}$ & herbácea & Martins 411, Martins 898 \\
\hline Pourouma guianensis Aubl. & & & & & $\mathrm{X}$ & arbórea & Magenta 241 \\
\hline Urera baccifera (L.) Gaudich. & & & & & $\mathrm{X}$ & arbustiva & Sampaio 480 \\
\hline \multicolumn{8}{|l|}{ VERBENACEAE } \\
\hline Lantana undulata Schrank & & $\mathrm{X}$ & $\mathrm{X}$ & & $\mathrm{X}$ & arbustiva & Martins 773, Sampaio 260 \\
\hline \multicolumn{8}{|l|}{ VITACEAE } \\
\hline Cissus sulcicaulis (Baker) Planch. & & & & & $\mathrm{X}$ & liana & Sampaio 473 \\
\hline C. verticillata (L.) Nicolson \& C.E. Jarvis & & & & & $\mathrm{X}$ & liana & Sampaio 620 \\
\hline \multicolumn{8}{|l|}{ XYRIDACEAE } \\
\hline Xyris jupicai Rich. & & & $\mathrm{X}$ & $\mathrm{X}$ & $\mathrm{X}$ & herbácea & Sampaio 287, Martins 426 \\
\hline X. savanensis Miq. & & & & $\mathrm{X}$ & & herbácea & Martins 764, Magenta 239 \\
\hline \multicolumn{8}{|l|}{ ZINGIBERACEAE } \\
\hline Renealmia petasites Gagnep. & & & & & $\mathrm{X}$ & herbácea & Martins 531, Sampaio 282 \\
\hline
\end{tabular}

apresenta o número de espécies e a freqüência das formas biológicas das fanerógamas encontradas na vegetação de restinga em Bertioga e em restingas situadas ao sul (Ilha do Mel) e ao norte (Picinguaba) da área de estudo.

As dez famílias mais importantes, com relação ao número de espécies, são: Orchidaceae, Myrtaceae, Bromeliaceae, Rubiaceae, Asteraceae, Fabaceae, Cyperaceae, Melastomataceae, Poaceae e Solanaceae.
Esta composição é bastante similar às apontadas por Pereira \& Araújo (2000), na comparação entre as restingas dos Estados do Espírito Santo, Rio de Janeiro, São Paulo, Paraná e Santa Catarina. Da mesma forma que nos estudos citados, a somatória das espécies destas famílias totaliza cerca de $50 \%$ do total das presentes nas áreas estudadas. Entre os gêneros, destacam-se Eugenia com 17 espécies, Mikania com 12 e Vriesea com 10. 
Tabela 2. Comparação dos dados florísticos obtidos neste trabalho aos das restingas da Ilha do Mel (Paraná) e de Picinguaba (São Paulo), Brasil.

\begin{tabular}{llll}
\hline Localidade & Ilha do Mel & Bertioga & Picinguaba \\
\hline Fonte & $\begin{array}{l}\text { S.M Silva } \\
\text { (dados não publicados) }\end{array}$ & Este estudo & $\begin{array}{l}\text { M.A. Assis } \\
\text { (dados não publicados) }\end{array}$ \\
$\mathrm{N}^{\circ}$ total de espécies fanerógamas & 555 & & 696 \\
Formas biológicas (\%) & Herbácea (41) & 611 & Arbórea (32) \\
& Arbórea (23) & Arbórea (30) & Herbácea (22) \\
& Epífita (14) & Epífita (15) \\
& Liana (11) & Arbúcea (27) & Liana (14) \\
& Arbustiva (10) & Epífita (15) & Outros (2) \\
& Outros (1) & Liana (15) & Orchidaceae (75) \\
& Orchidaceae (51) & Arbustiva (13) & Asteraceae (74) \\
& Poaceae (47) & Outros (1) & Fabaceae (58) \\
& Asteraceae (35) & Orchidaceae (45) & Rubiaceae (42) \\
& Fabaceae (33) & Myrtaceae (39) & Melastomataceae (36) \\
& Bromeliaceae (32) & Bromeliaceae (36) & Myrtaceae (33) \\
& Myrtaceae (31) & Pubiaceae (34) & Piperaceae (16) \\
& Cyperaceae (28) & Asteraceae (34) & Bignoniaceae (15) \\
& Rubiaceae (23) & Pabaceae (33) & Poaceae (15) \\
& Melastomataceae (13) & Cyperaceae (22) & Euphorbiaceae (13)
\end{tabular}

Em relação às formas biológicas, em Bertioga houve predomínio das arbóreas com 195 espécies. Myrtaceae, com 39 espécies, destaca-se como a família de maior riqueza específica (20\% das arbóreas). Apesar do predomínio de arbóreas, estas representam apenas cerca de $30 \%$ das espécies da flora das restingas citadas na Tab. 1. Em levantamentos de Floresta Ombrófila Densa, as árvores representam cerca de $50 \%$ do total de fanerógamas (Lima \& Guedes-Bruni 1994; Ivanauskas 2001). Tais resultados refletem a formação de mosaicos de vegetação que apresentam um gradiente entre formações campestres e florestais, que em geral são menos densas, aumentando a disponibilidade de luz nos estratos inferiores e favorecendo o epifitismo.

Como espécies arbóreas comuns nas restingas do Estado de São Paulo, destacam-se Amaioua intermedia, Andira fraxinifolia, Calophyllum brasiliense, Clusia criuva, Eugenia stigmatosa, Guapira opposita, Ilex theezans, Ilex dumosa, Maytenus robusta, Myrcia multiflora, Nectandra oppositifolia, Ocotea pulchella, Pera glabrata, Psidium cattleyanum, Tabebuia cassinoides e Tapirira guianensis. Estes táxons ocorrem em mais de 75\% dos levantamentos consultados (De Grande \& Lopes 1981; Mantovani 1992; Sugiyama 1998a; Carvalhaes \& Mantovani 1998; Guedes et al. 2006;
M.A. Assis, dados não publicados, e o presente estudo). A maioria deles apresenta ampla distribuição geográfica, ocorrendo em vários ecossistemas do Estado de São Paulo, com exceção de Tabebuia cassinoides e Eugenia stigmatosa que são restritas à restinga e à Floresta Ombrófila Densa.

As herbáceas estão representadas por 181 espécies (27\% do total), com destaque para Cyperaceae (23 espécies) e Poaceae (19), ocorrendo principalmente em Praia e Dunas, Escrube e em áreas degradadas ou em regeneração. No estrato herbáceo das formações florestais, as famílias com maior riqueza em espécies são: Orchidaceae (12), Rubiaceae (10), Bromeliaceae (nove) e Acanthaceae (oito).

As seguintes herbáceas podem ser consideradas raras no Estado de São Paulo: Plantago catharinea e Portulaca striata, ocorrentes na fisionomia de Praia e Dunas, e Schultesia gracilis, em terrenos arenosos de locais degradados. Duas espécies representaram o primeiro registro para o Estado: Tonina fluviatilis e Syngonanthus chrysanthus (Eriocaulaceae), a primeira ocorrendo em beira de trilhas, e a segunda sobre terrenos alterados, com solos residuais sujeitos ao encharcamento.

As epífitas somam 96 espécies, representando $15 \%$ da flora analisada, e apresentam Orchidaceae (35), Bromeliaceae (34) e Araceae (11) como as famílias 
com maior riqueza. Muitas epífitas podem também apresentar hábito terrestre.

Considerando a elevada umidade da região e a menor densidade do dossel das fisionomias florestais, já era esperada uma elevada riqueza em epífitas. A mesma tendência é observada na Ilha do Mel e em Picinguaba. Nestes locais, embora a precipitação anual seja um pouco inferior, o ambiente é úmido durante todo o ano e a proporção de epífitas é praticamente a mesma que a observada em Bertioga (Tab. 1). Em proporção um pouco menor, o favorecimento ao desenvolvimento dessas plantas foi observado em levantamentos efetuados em Floresta Ombrófila Densa (Ivanauskas 2001; Groppo 2005; Garcia 2005). Vale lembrar que em regiões com períodos de estiagem bem definidos, como em Floresta Estacional Semidecidual e Cerrados, a proporção de epífitas chega a menos de 1\% (Mantovani \& Martins 1993; Batalha et al. 1997; Stranguetti \& Taroda-Ranga 1998).

Entre os 96 representantes de lianas, as famílias com maior número de espécies são: Asteraceae, com 15 espécies e Malpighiaceae e Fabaceae, com nove espécies cada. As lianas representam para a flora desta região $15 \%$ das espécies, valor próximo ao de outros levantamentos efetuados em restinga e em Floresta Ombrófila Densa, enquanto que na Floresta Estacional Semidecidual, estas contribuem com cerca de $40 \%$ das espécies (P.S.P. Sampaio, dados não publicados). Como lianas características de restinga, destacam-se Bomarea edulis, Calopogonium mucunoides, Centrosema virginianum, Dioscorea monadelpha, Elachyptera micrantha, Ipomoea phyllomega, Ipomoea tiliacea, Jacquemontia blanchetii, Matelea denticulata, Mikania argyreiae, Mikania involucrata, Oxypetalum alpinum, Oxypetalum banksii, Piptocarpha leprosa, Stigmaphyllon arenicola e Stigmaphyllon ciliatum.

As plantas de hábito arbustivo totalizaram 89 espécies, correspondendo a cerca de $13 \%$ do número total de espécies, sendo Rubiaceae (14 espécies) e Melastomataceae (10) as famílias mais representativas.

Aspectos das comunidades vegetais de restinga - A variação na vegetação de restinga, refletida nas diversas fitofisionomias estudadas, está intimamente relacionada à variação dos fatores abióticos presentes neste ecossistema - tipo de substrato (arenoso, orgânico), níveis de nutrientes e salinidade, profundidade do lençol freático, proximidade da praia ou de manguezais, regime hídrico, entre outros (Henriques et al. 1986; Silva \& Britez 2005).
A classificação adotada na Resolução CONAMA 07/96, no entanto, não abrange todas as fisionomias encontradas na região de Bertioga, ocorrendo diferenças no padrão florístico (espécies predominantes), na caracterização do substrato (presença de turfa, espessura da camada de serapilheira) e regime de inundação. Essas diferenças foram verificadas no Escrube, com uma espessura maior da camada de serapilheira; na Floresta Alta de Restinga, com pequenas diferenças na composição florística e também na espessura da camada de serapilheira. Na fisionomia de Vegetação Entre Cordões, houve correspondência apenas na composição florística. Em Bertioga, existe uma formação florestal que não se enquadra em nenhuma classe estabelecida pelo CONAMA, diferindo da Floresta Paludosa sobre Substrato Turfoso, pelo regime de inundação, que aqui é temporário, e pela ausência de turfeiras. Para esta formação foi então adotada a denominação preliminar de Floresta Alta de Restinga Úmida, proposta por Souza (2006).

Praias e dunas - As praias e dunas são ocupadas por vegetação herbácea a subarbustiva, numa estreita faixa paralela ao mar, em substrato arenoso, com serapilheira inexistente ou inconspícua. Nas praias, nas porções mais elevadas, as plantas crescem sobre substrato móvel e freqüientemente atingido pelas marés de sizígia, compostas principalmente por espécies herbáceas reptantes, rizomatosas e cespitosas, de $40 \mathrm{~cm}$ de altura. Nesta fisionomia foram amostradas, na praia de Itaguaré, 33 espécies, das quais se destacam, como exclusivas: Acicarpha spathulata, Ambrosia elatior, Blutaparon portulacoides, Cenchrus echinatus, Chloris retusa, Ipomoea imperati, Ipomoea pes-caprae, Sporobulus virginicus e Stenotaphrum secundatum.

A vegetação da anteduna, ocorrendo sobre terraços não atingidos pelas marés, é mais fechada e composta por espécies herbáceas a subarbustivas, com até $60 \mathrm{~cm}$ de altura. Em Bertioga foram encontradas, como plantas características desta fisionomia, as seguintes espécies: Cenchrus echinatus, Centrosema virginianum, Chloris retusa, Desmodium incanum, Diodella radula, Polygala cyparissias, Richardia brasiliensis, Sebastiania corniculata, Sphagneticola trilobata, Sporobulus virginicus, Stigmaphyllon arenicola e Stylosanthes viscosa.

Escrube - Formação arbustiva fechada, bastante densa, com altura de 1 a 4 metros, modelada pelo vento e exposta à salinidade proveniente de borrifos 
marinhos, ocupando o primeiro cordão arenoso. A camada de serapilheira é relativamente espessa (cerca de $4 \mathrm{~cm}$ ), porém a camada orgânica do substrato é muito fina (menos que $0,5 \mathrm{~cm}$ de espessura). Esta descrição corresponde a área de Escrube encontrada na região da praia de Itaguaré, onde foram identificadas 101 espécies. Na região mais próxima à praia, a vegetação é composta por espécies herbáceas, arbustivas e arbóreas nanificadas, com predominância de Ananas fritzmuelleri, Bromelia antiacantha, Cordia curassavica, Dalbergia ecastaphyllum, Epidendrum fulgens, Guapira opposita, Heteropterys aenea, Heteropterys intermedia, Lantana undulata, Mikania micrantha, Paullinia micrantha, Psidium cattleyanum, Quesnelia arvensis, Schinus terebinthifolius, Smilax elastica, Sophora tomentosa, Tetracera sellowiana e Tibouchina clavata. Em direção ao interior, a vegetação torna-se mais alta, com espécies arbustivas e pequenas árvores, como Eugenia speciosa, Guapira opposita, Maytenus littoralis, Psidium cattleyanum, Schinus terebinthifolius e Tocoyena bullata.

Floresta Alta de Restinga - Ocupa grande parte da área de estudo, situando-se na praia de Itaguaré e na porção interior de Guaratuba. Foi caracterizada como uma formação florestal predominantemente arbórea com dossel fechado, sobre substrato arenoso escuro devido à presença de matéria orgânica até cerca $45 \mathrm{~cm}$ de profundidade. Apresenta uma camada delgada de serapilheira (menos que $1 \mathrm{~cm}$ de espessura), recobrindo uma trama de raízes superficiais com cerca de $10 \mathrm{~cm}$ de espessura. O terreno, embora geralmente não inundável, apresenta depressões inundáveis durante o período chuvoso. O dossel tem 15 a $18 \mathrm{~m}$ de altura, com árvores emergentes que podem atingir até $25 \mathrm{~m}$. Os estratos são bem definidos e possuem grande quantidade e riqueza de epífitas, representadas principalmente por orquidáceas, bromeliáceas e aráceas. A Floresta Alta de Restinga apresenta grande riqueza florística, totalizando 301 espécies, das quais as formas biológicas predominantes em número de espécies são as arbóreas, com $40 \%$ do total, herbáceas com $20 \%$ e epífitas $19 \%$. O dossel é formado principalmente por Heisteria silvianii, Humiriastrum dentatum, Licania nitida, Maprounea guianensis, Nectandra oppositifolia, Ocotea aciphylla, Ocotea teleiandra, Schefflera angustissima, Sloanea guianensis e Xylopia brasiliensis. Entre as emergentes, destacam-se Manilkara subsericea,
Balizia pedicellaris, Syagrus pseudococos e Eriotheca pentaphylla. No estrato médio são muito freqüentes as mirtáceas, tais como Eugenia oblongata, Eugenia riedeliana, Eugenia sulcata e Eugenia velutiflora. Também podem ser citadas Garcinia gardneriana, Guapira opposita, Guapira nitida, Guatteria hilariana e Podocarpus sellowii, entre outras. O estrato herbáceo é composto principalmente por bromeliáceas, formando um mosaico de manchas uniespecíficas, constituídas por Ananas fritzmuelleri, Nidularium innocentii e Quesnelia arvensis.

Floresta Alta de Restinga Úmida - Esta fisionomia, situada sobre paleolagunas colmatadas que se estendem em praticamente toda região existente entre a rodovia SP-55 e o sopé da Serra do Mar é a mais extensa entre as estudadas aqui. Foi caracterizada como uma formação florestal com fisionomias bastante diversificadas, relacionadas principalmente à oscilação do lençol freático ao longo do ano. O substrato é variável, com uma camada superficial de matéria orgânica humificada, variando de cerca de $20 \mathrm{~cm}$ a mais de 1 metro de profundidade, podendo ocorrer lentes de material argiloso. O solo é inundável na época de chuvas, e mantém o lençol freático praticamente aflorante, em geral a cerca de $15-30 \mathrm{~cm}$ de profundidade, mesmo nos períodos mais secos. A camada de serapilheira é fina (menos de $1 \mathrm{~cm}$ de espessura). A trama de raízes superficiais é densa, com 5-8 cm de espessura. Muitos indivíduos arbóreos apresentam raízes tabulares e o sistema radicular superficial. Nas áreas inundadas durante períodos mais curtos (somente na estação chuvosa), a floresta possui dossel de fechado a aberto e altura em torno de 15 a 17 metros, com emergentes de até $27 \mathrm{~m}$. Em alguns trechos a estratificação é pouco definida. Nesta categoria fisionômica foram encontradas 434 espécies, sendo $37 \%$ arbóreas, $22 \%$ herbáceas, $17 \%$ epífitas e $17 \%$ lianas. É a formação de maior riqueza em espécies entre as fisionomias estudadas em Bertioga. A composição do dossel é variável, muitas vezes havendo dominância de uma ou outra espécie. Entre as mais características deste estrato, destacam-se: Alchornea triplinervia, Balizia pedicellaris, Calophyllum brasiliense, Eriotheca pentaphylla, Eugenia sulcata, Manilkara subsericea, Marlierea cf. parviflora, Nectandra oppositifolia, Schefflera angustissima, Sloanea guianensis, Tabebuia cassinoides e Tabebuia umbellata. Como componente do subdossel, são encontradas Amaioua 
intermedia, Calyptranthes concinna, Diospyros brasiliensis, Euterpe edulis, Garcinia gardneriana, Gomidesia shaueriana, Guapira opposita, Eugenia neolanceolata, Eugenia riedeliana, Marlierea obscura, Marlierea tomentosa, Myrcia acuminatissima e diversas outras mirtáceas. As emergentes, com alturas entre 19 e 23 m (às vezes chegando aos $27 \mathrm{~m}$ ), são representadas por Balizia pedicellaris, Calophyllum brasiliense, Eriotheca pentaphylla, Manilkara subsericea e Tapirira guianensis. No sub-bosque, dominam Bactris setosa, Endlicheria paniculata, Euterpe edulis, Guarea macrophylla, Ixora burchelliana, Miconia fasciculata, Mollinedia schottiana, Psychotria carthagenensis, entre outras rubiáceas. O solo, em alguns trechos menos inundáveis, encontra-se recoberto principalmente por bromeliáceas (Nidularium innocentii, Nidularium procerum), marantáceas (Calathea communis), rubiáceas e pteridófitas. As epífitas ocorrem em grande quantidade de indivíduos e são representadas por bromeliáceas (Aechmea, Nidularium, Tillandsia, Vriesea), gesneriáceas (Codonanthe, Nematanthus), orquidáceas, aráceas e ciclantáceas (Thoracocarpus bissectus). Dentre as lianas, são comuns Forsteronia leptocarpa, Mucuna urens e Parabignonia unguiculata. Nos trechos onde a água permanece aflorante por períodos mais longos do ano, tais como as beiras de córregos e depressões do terreno, a vegetação florestal é baixa, com altura em torno dos 6 metros, apresentando indivíduos bastante ramificados, dossel aberto, estratos pouco definidos e presença de espécies arbóreas higrófilas, tais como Coussapoa microcarpa, Eugenia monosperma, Garcinia gardneriana, Inga edulis, Maytenus littoralis, Randia armata e Tocoyena bullata.

Vegetação Entre Cordões - É uma fisionomia herbáceo-arbustiva aberta, localizada sobre substrato arenoso consolidado, inundável. Naturalmente, ocorreriam nos Entre Cordões arenosos e em áreas originadas de assoreamento de antigas lagoas, lagunas e braços de rio ou pelo afloramento de lençol freático. $\mathrm{Na}$ região de estudo, no entanto, foi encontrada somente nos locais onde houve extração de areia dos cordões arenosos, desenvolvendo-se sobre a piçarra remanescente, que é bastante impermeável. Sua inclusão nesta classe da Resolução CONAMA, deveu-se exclusivamente às semelhanças na composição florística. Nestes locais degradados existe uma comunidade vegetal bastante peculiar, composta principalmente por Drosera capillaris, Eleocharis filiculmis, Eleocharis geniculata, Eleocharis nana, Fimbristylis miliacea, Syngonanthus chrysanthus, Tibouchina clavata, Tibouchina urvilleana, Xyris jupicai e Xyris savanensis, Pequenas árvores também podem ser encontradas, tais como Ilex pseudobuxus, Myrcia palustris, Rapanea ferruginea e Tocoyena bullata. Nas épocas chuvosas, pode ficar coberta por uma lâmina d'água, com o desenvolvimento de plantas aquáticas, como Nymphoides indica e Utricularia gibba. Estas comunidades, de ocorrência muito restrita, apresentam reduzida riqueza florística, totalizando 45 espécies, com predomínio de plantas herbáceas $(77 \%$ das espécies); tal fato reflete as condições edáficas, que condicionam uma vegetação especializada, tolerante à inundação e à compactação e pobreza do substrato.

Outras fisionomias - Além das fisionomias já descritas, ocorrem ainda o Brejo de Restinga, a Floresta Paludosa (caxetal) e a Floresta Baixa de Restinga, as quais são bastante restritas e pouco desenvolvidas nesta região, apresentando-se associadas às demais fisionomias. Por restrições quanto ao acesso, as duas primeiras foram pouco amostradas, não permitindo uma descrição mais pormenorizada. O Brejo de Restinga é uma formação herbácea, do tipo graminóide, que ocorre em áreas próximas aos rios, muitas vezes ocupando meandros abandonados; com lençol freático aflorante praticamente o ano todo, é composto predominantemente por um número restrito de espécies tolerantes ao encharcamento do solo, com predominância de representantes da família Cyperaceae, tais como Cyperus ligularis e Rhynchospora corymbosa. A Floresta Paludosa é uma formação arbórea aberta, permanentemente inundada, conhecida como caxetal, com árvores de até 8 metros de altura, sem estratificação. Apresenta como espécie dominante Tabebuia cassinoides, restringindo-se a pequenos trechos situados à margem do rio Itaguaré.

A Floresta Baixa de Restinga é pouco significativa, ocupando uma faixa estreita que representa uma transição entre o Escrube e a Floresta Alta de Restinga, sendo de difícil reconhecimento em campo.

Considerações sobre a conservação das restingas em Bertioga - Os ecossistemas de restinga são ambientes complexos e ao mesmo tempo frágeis, refletindo de forma direta os condicionantes edáficos, podendo ser profundamente afetados pelo desmatamento e pela alteração do regime hídrico do solo. Os solos arenosos da restinga são, em geral, altamente lixiviados, com 
baixa capacidade de retenção de cátions, pobres em nutrientes e com predominância de alumínio na fase trocável do solo. Considerando que nos solos arenosos das restingas: 1) o principal reservatório de nutrientes são as próprias plantas; 2) o folhedo acumulado é importante mecanismo e o principal responsável pela retenção de nutrientes no solo; 3) o crescimento superficial das raízes também ajuda a manter os nutrientes por mais tempo no solo (Hay \& Lacerda 1984), além de aumentar a eficiência da absorção desses nutrientes na interface serapilheira-solo, a retirada da vegetação e, principalmente, da serapilheira e da camada superficial do solo pode resultar num expressivo atraso do processo sucessional nas restingas, podendo ser considerado uma condição irreversível em curto e médio prazos.

Na região estudada, há áreas ocupadas originalmente por floresta, em que o desmatamento ocorreu há mais de 30 anos e que permanecem com uma vegetação herbácea, apesar de estarem cercados por matas preservadas que garantiriam o constante aporte de propágulos.

Locais onde intervenções viárias e aterros provocaram o represamento das águas podem rapidamente perder a cobertura original, transformando-se em brejos antrópicos com a predominância de Hedychium coronarium e Typha dominguensis, espécies invasoras dos ambientes palustres, que impedem ou retardam a regeneração da vegetação nativa.

As grandes áreas de restingas ainda intactas em Bertioga encontram-se fora de unidades de conservação e, em sua maioria, estão ameaçadas pelo avanço de áreas urbanas e empreendimentos imobiliários. A conservação destes ecossistemas e dos gradientes ecológicos entre as praias e a Serra do Mar é necessária para garantir a conservação dos recursos genéticos da flora local.

Foram amostradas na região estudada espécies com poucos materiais representativos nos herbários ou com distribuição geográfica restrita, algumas delas consideradas por taxonomistas como registros importantes para a espécie no Estado. Destacam-se, entre as arbóreas, Coccoloba fastigiata, Diospyros brasiliensis, Eugenia copacabanensis, Eugenia crassiflora, Eugenia disperma, Eugenia velutiflora, Guapira nitida, Huberia ovalifolia, Inga praegnans, Ladenbergia hexandra, Licania nitida, Mollinedia oligantha, Myrcia macrocarpa, Myrcia palustris, Ocotea lobbii, Styrax glaber, Tetraplandra riedelii e Tocoyena bullata. Como lianas raras foram registradas Aegiphila fluminensis, Dalbergia sampaioana, Jobinia connivens, Mikania eriostrepta, Mikania hastato-cordata, Mikania ternata, Tetracera sellowiana e Wilbrandia ebracteata. Dentre os arbustos, apenas Croton sphaerogynus, Dendropanax exilis e Rudgea coronata subsp. coronata podem ser consideradas de ocorrência restrita no Estado. Entre herbáceas podem ser consideradas raras: Plantago catharinea e Portulaca striata, ambas ocorrentes na fisionomia de Praia e Dunas, além de duas espécies que representaram o primeiro registro para o Estado: Tonina fluviatilis e Syngonanthus chrysanthus, a primeira ocorrendo em beira de trilhas, e a segunda sobre terrenos alterados, com solos residuais sujeitos ao encharcamento.

Algumas das espécies estão citadas na lista das espécies ameaçadas de extinção do Estado de São Paulo (SMA 2004): Croton sphaerogynus (em perigo) e Billbergia pyramidalis, Eugenia copacabanensis, Eugenia disperma, Eugenia velutiflora, Euterpe edulis, Ladenbergia hexandra, Plantago catharinea e Portulaca striata (vulneráveis).

A presença destas espécies faz das restingas de Bertioga uma região prioritária para a preservação da flora, requerendo medidas especiais de conservação de forma a impedir que o acelerado processo de destruição de seus hábitats, devido à expansão dos desmatamentos para ocupação imobiliária, venha comprometer as populações autóctones destas espécies.

\section{Agradecimentos}

Aos especialistas, pelo auxílio na identificação de espécies: Acanthaceae: Cíntia Kameyama; Alstroemeriaceae: Marta Assis; Amaryllidaceae: Julie Dutihl; Annonaceae: Renato Mello-Silva; Apocynaceae: Alessandro Rapini, Tatiana Konno; Aquifoliaceae: Milton Groppo; Araceae: Eduardo Gonçalves, Eduardo Catharino, Marcus Nadruz, Livia Temponi; Araliaceae: Pedro Fiaschi; Arecaceae: Amauri Marcato; Asteraceae: João Semir, Roberto Esteves, Mara Ritter; Begoniaceae: Sandra Jules Gomes da Silva, Eliane Jacques; Bignoniaceae: Marta Assis; Bromeliaceae: Maria das Graças Lapa Wanderley, João Vicente Coffani-Nunes, Bianca Moreira, Suzana Proença, Viviane Oliveira, Andrea Costa; Cactaceae: Daniela Zappi, Eduardo Catharino; Fabaceae: Haroldo Lima; Celastraceae: Rita Carvalho-Okano; Chrysobalanaceae: Ghillean Prance; Convolvulaceae: Rosângela Simão- 
Bianchini; Combretaceae: Iracema Loiola; Cyperaceae: Marccus Alves, Ana Paula Prata, Celi Muniz, Ana Cláudia Araújo; Dioscoreaceae: Mizué Kirizawa; Eriocaulaceae: Ana Maria Giulietti, Daniela Zappi, Lara Parra; Euphorbiaceae, Gentianaceae e Phyllanthaceae: Inês Cordeiro; Gesneriaceae: Alain Chautems; Heliconiaceae: Eduardo Catharino; Iridaceae: Lindolpho Capellari Jr.; Juncaceae: Marccus Alves; Lamiaceae: Raymond Harley; Lauraceae: João Batista Baitello, Sueli Nicolau; Loganiaceae: Daniela Zappi; Malpighiaceae: André Amorim, Maria Cândida Mamede, Alessandro Rapini; Malvaceae: Gerleni Esteves; Marantaceae: Silvana Vieira, Rafaela Forzza; Melastomataceae: José Fernando Baugratz, Maria Leonor Souza, Silvia Chiea; Meliaceae: João Aurélio Pastore; Moraceae e Urticaceae: Sérgio Romaniuc Neto; Myrtaceae: Maria Lúcia Kawasaki, Marcos Sobral, Osni Aguiar; Nyctaginaceae: Antonio Furlan; Onagraceae: Marilia Duarte; Orchidaceae: Fábio Barros, Eduardo Catharino; Plantaginaceae e Scrophulariaceae: Vinícius Castro Souza; Poaceae: Ana Zanin, Carlos Garcia; Portulacaceae: Antonio Furlan; Rubiaceae: Elisete Anunciação, Cristina Bestetti Costa, Daniela Zappi; Rutaceae: José Rubens Pirani; Santalaceae, Marie Sugiyama; Sapindaceae: Genise Somner; Sapotaceae: Maria Margarida Fiúza de Melo; Solanaceae: João Renato Stehmann; Styracaceae: Reinaldo Monteiro; Xyridaceae: Maria das Graças Lapa Wanderley. Aos biólogos, por participação nas coletas: Ana Girardi, Alexandra Boldrin, André Rovai, Bruno Kamada, Caroline Parreira, Daniela Guedes, Elisabeth Lima, Elisabete Lopes, Márcio Subtil, Marie Sugiyama, Matheus Rotundo, Rafael Louzada, Raquel Gonçalves, Zélia Mello. À geóloga Célia Gouveia Souza, pelos esclarecimentos sobre aspectos geológicos da região; ao biólogo Bolívar Barbante e ao Eduardo Lustosa, pela sugestão das áreas de estudo; ao Sr. Manoel Pinto, pela autorização dos trabalhos de campo em sua propriedade.

\section{Referências bibliográficas}

Andrade, M.A.B. \& Lamberti, A. 1965. A vegetação. Pp.151201. In: A. Azevedo (ed.). A Baixada Santista: aspectos geográficos. As bases físicas. v. 1. São Paulo, EDUSP.

APG II. 2003. An update of APG classification for the orders and families of flowering plants. Botanical Journal of the Linnean Society 141: 399-436.

Araújo, D.S.D. 1984. Comunidades vegetais. P. 157. In: L.D. Lacerda, D.S.D.Araújo, R. Cerqueira \& B. Turq (orgs.). Restingas; origem, estrutura, processos. Niterói, CEUFF.
Araújo, D.S.P. 1987. Restingas: Síntese do conhecimento para a costa sul-sudeste brasileira. Pp. 333-334. In: Anais do I Simpósio sobre Ecossistemas da Costa Sul e Sudeste Brasileira. v. 1. Águas de Lindóia. São Paulo, ACIESP.

Araújo, D.S.D. \& Henriques, R.P.B. 1984. Análise florística das restingas do Estado do Rio de Janeiro. Pp.159-193. In: L.D. Lacerda; D.S.D. Araújo; R. Cerqueira \& B. Turq (orgs.). Restingas; origem, estrutura, processos. Niterói, CEUFF.

Batalha, M.A.; Aragaki, S. \& Mantovani, W. 1997. Florística do cerrado em Emas (Pirassununga, SP). Boletim de Botânica da Universidade de São Paulo 16: 49-64.

Carvalhaes, M. \& Mantovani, W. 1998. Florística de mata sobre restinga na Juréia, Iguape, SP. Pp. 37-48. In: Anais do IV Simpósio de Ecossistemas Brasileiros. v. 1. Águas de Lindóia, São Paulo, ACIESP.

Cerqueira, R. 2000. Biogeografia das Restingas. Pp. 65-75. In: F.A. Esteves \& L.D. Lacerda (eds.). Ecologia de restingas e lagoas costeiras. Macaé, NUPEN / UFRJ.

Cesar, O. \& Monteiro, R. 1995. Florística e fitossociologia de uma floresta de restinga em Picinguaba (Parque Estadual da Serra do Mar), Município de Ubatuba-SP. Naturalia 20: 89-105.

CONAMA. Conselho Nacional do Meio Ambiente (Brasil). 1996. Anexo da Resolução CONAMA 07/96, de 23 de julho de 1996. Diário Oficial da União. Brasília. Publicado em 26.08.1996.

De Grande, D.A. \& Lopes, E.A. 1981. Plantas da restinga da Ilha do Cardoso (São Paulo, Brasil). Hoehnea 9: 1-22.

França, F.S. \& Rolim, S.G. 2000. Estrutura de um trecho de floresta de restinga no Município de Bertioga (SP). Pp. 84-91. In: Anais do V Simpósio de Ecossistemas Brasileiros: Conservação. v. 3. Vitória. São Paulo, ACIESP.

Furlan, A.; Monteiro, R.; Cesar, O. \& Timoni, J.L. 1990. Estudos florísticos das matas de restinga de Picinguaba, SP. Pp. 220-227. In: Anais do II Simpósio de Ecossistemas da Costa Sul e Sudeste Brasileira: estrutura, função e manejo. v. 3. Águas de Lindóia. São Paulo, ACIESP.

Garcia, F.C.P. \& Monteiro, R. 1993. Espécies de Leguminosae na planície litorânea arenosa em Picinguaba, UbatubaSP. Pp. 107-114. In: Anais do III Simpósio de Ecossistemas da Costa Brasileira: subsídio a um gerenciamento ambiental. v. 3. Serra Negra. São Paulo, ACIESP.

Garcia, R.J.F. \& Pirani, J.R. 2005. Análise florística, ecológica e fitogeográfica do Núcleo Curucutu, Parque Estadual da Serra do Mar (São Paulo, SP), com ênfase nos campos junto à crista da Serra do Mar. Hoehnea 32: 1-48.

Girardi, A.C.S.; Santos, R.F. \& Mantovani, W. 2005. Subsídios metodológicos para o planejamento e gestão de restingas - Estudo de caso - Bertioga, SP. Pp. 321-344. In: W. Mantovani. (org.). Caminhos de uma ciência ambiental. São Paulo, Annablume.

Groppo, M. \& Pirani, J.R. 2005. Levantamento florístico das espécies de ervas, subarbustos, lianas e hemiepífitas da mata da Reserva da Cidade Universitária. Boletim de Botânica da Universidade de São Paulo 23: 141-233. 
Guedes, D.; Barbosa, L.M. \& Martins, S.E. 2006. Composição florística e estrutura fitossociológica de dois fragmentos de floresta de restinga no município de Bertioga, SP, Brasil. Acta Botanica Brasilica 20: 299-312.

Hay, J.D. \& Lacerda, L.D. 1984. Ciclagem de nutrientes no ecossistema de restinga. Pp.159-193. In: L.D. Lacerda; D.S.D.Araújo; R. Cerqueira \& B. Turq (orgs.). Restingas: origem, estrutura, processos. Niterói, CEUFF.

Henriques, R.P.B.; Araújo, D.S.D. \& Hay, J.D. 1986. Descrição e classificação dos tipos de vegetação da restinga de Carapebus, Rio de Janeiro. Revista Brasileira de Botânica 9: 173-189.

Ivanauskas, N.M.; Monteiro, R.; Rodrigues, R.R. 2001. Levantamento florístico de um trecho de Floresta Atlântica em Pariquera-Açu, São Paulo - Brasil. Naturalia 26: 97-129.

Kirizawa, M.; Lopes, E.A.; Pinto, M.M.; Lam, M. \& Lopes, M.I.M.S. 1992. Vegetação da Ilha Comprida: aspectos físionômicos e florísticos. Pp. 386-391. In: Anais do II Congresso Nacional sobre Essências Nativas. v. 4. São Paulo, IF.

Lacerda, L.D. \& Esteves, F.A. 2000. Apresentação Restingas brasileiras: Quinze anos de estudos. Pp. IIVII. In: F.A. Esteves \& L.D. Lacerda (eds.). Ecologia de restingas e lagoas costeiras. Macaé, NUPEM / UFRJ.

Lima, M.P.M. \& Guedes-Bruni, R.R. (orgs.). 1994. Reserva Ecológica de Macaé de Cima, Nova Friburgo - RJ: aspectos florísticos das espécies vasculares. Rio de Janeiro, Jardim Botânico, v.1.

Mantovani, W. 1992. A vegetação sobre a restinga de Caraguatatuba, SP. Pp. 139-144. In: Anais do II Congresso Nacional sobre Essências Nativas. v. 4. São Paulo, IF.

Mantovani, W. \& Martins, F.R. 1993. Florística do cerrado na Reserva Biológica de Mogi-Guaçu, SP. Acta Botanica Brasilica 7: 33-60.

Pereira, O.J. 1990. Caracterização fitofisionômica da restinga de Setiba, Guarapari, Espírito Santo. Pp. 207-219. In: Anais do II Simpósio da Costa Sul e Sudeste Brasileira. v. 3. Águas de Lindóia. São Paulo, ACIESP.

Pereira, O.B. \& Araújo, D.S.D. 2000. Análise florística das restingas dos Estados do Espírito Santo e Rio de Janeiro. Pp. 25-63. In: F.A. Esteves \& L.D. Lacerda (eds.). Ecologia de Restingas e Lagoas Costeiras. Macaé, NUPEN / UFRJ.

Ribeiro, J.E.L.S. \& Monteiro, R. 1993. Diversidade das orquídeas (Orchidaceae) da planície litorânea da Praia da Fazenda (Vila de Pinciguaba, Município de Ubatuba, SP) e ocorrência no litoral brasileiro. Pp. 99-106. In: Anais do III Simpósio de Ecossistemas da Costa Brasileira: subsídio a um gerenciamento ambiental. v. 3. Serra Negra. São Paulo, ACIESP.

Romero, R. \& Monteiro, R. 1993. Ocorrência da família Melastomataceae na planície litorânea de Picinguaba, município de Ubatuba, São Paulo. Pp.115-123. In: Anais do III Simpósio de Ecossistemas da Costa Brasileira: subsídio a um gerenciamento ambiental. v. 3. Serra Negra. São Paulo, ACIESP.
Sentelhas, P.C.; Pereira, A.R.; Marin, F.R.; Angelocci, L.R.; Alfonsi, R.R.; Caramori, P.H. \& Swart, S. 1999. Balanços hídricos climatológicos do Brasil - 500 balanços hídricos de localidades brasileiras. http:// www.bdclima.cnpm.embrapa.br/resultados/ balanco.php? UF $=$ sp\&COD $=450 . \quad$ (Acesso em: 10/julho/2006).

Setzer, J. 1966. Atlas climatológico do Estado de São Paulo. Comissão Interestadual da Bacia do Paraná-Paraguai. São Paulo, CESP.

Silva, I.X.; Moraes, R.P.; Santos, R.P.; Pompéia, S.L. \& Martins, S.E. 1993. A degradação dos ecossistemas da Baixada Santista, São Paulo. Pp. 129-140. In: Anais do III Simpósio de ecossistemas da costa brasileira: subsídio a um gerenciamento ambiental. v. 3. Serra Negra. São Paulo, ACIESP.

Silva, S.M. \& Britez, R.M. 2005. A vegetação da planície costeira. Pp. 49-84. In: M.C.M. Marques \& R.M. Britez (orgs.). História natural e conservação da Ilha do Mel. Curitiba, UFPR.

SMA. Secretaria do Meio Ambiente (São Paulo). 2004. Lista oficial das espécies da flora do Estado de São Paulo ameaçadas de extinção. Resolução SMA 48, de 21 de setembro de 2004. Diário Oficial do Estado de São Paulo - Meio Ambiente. Publicado em 22.09.2004.

Souza, C.R.G. 2006. Mapeamento de compartimentos fisiográficos de planície costeira e baixa-encosta e da vegetação associada, no Litoral Norte de São Paulo. In: VI Simpósio Nacional de Geomorfologia. Goiânia, UGB. (CD-ROM - trabalho completo)

Souza, C.R.G.; Bendazoli, A.; Sugiyama, M.; Lopes, E.A. \& Kirizawa, M. 1997. A relação entre o meio físico e a biota no estudo da "restinga" do Estado de São Paulo. Pp. 367-372. In: Resumos expandidos do VI Congresso da ABEQUA e Reunião sobre o Quaternário da América do Sul. Curitiba, ABEQUA.

Souza, V.C. \& Capellari Jr., L. 2004. A vegetação das dunas e restingas da Estação Ecológica Juréia-Itatins. Pp. 103-114. In: O.A.V. Marques \& W. Duleba (eds.). Estação Ecológica Juréia-Itatins: Ambiente físico, flora e fauna. Ribeirão Preto, Holos.

Stranghetti, V. \& Taroda-Ranga, N. 1998. Levantamento florístico das espécies vasculares da floresta estacional mesófila semidecídua da Estação Ecológica de Paulo Faria-SP. Revista Brasileira de Botânica 21: 289-298.

Sugiyama, M. 1998a. Estudo de florestas da restinga da Ilha do Cardoso, Cananéia, São Paulo, Brasil. Boletim do Instituto de Botânica 11: 119-159.

Sugiyama, M. 1998b. Composição e estrutura de três estratos de trecho de floresta de restinga, Ilha do Cardoso, Cananéia, SP. Pp. 140-146. In: Anais do IV Simpósio de Ecossistemas Brasileiros. v. 3. Águas de Lindóia. São Paulo, ACIESP. 
274 Martins, Rossi, Sampaio \& Magenta: Caracterização florística de comunidades vegetais de restinga em Bertioga...

Sugiyama, M. \& Mantovani, W. 1993. Fitossociologia de um trecho de mata de restinga na Ilha do Cardoso, SP. Pp. 49-57. In: Anais do III Simpósio de Ecossistemas da Costa Brasileira: subsídio a um gerenciamento ambiental. v. 3. Serra Negra. São Paulo, ACIESP.

Suguio, K. \& Martin, L. 1987. Classificação de costas e evolução geológica das planícies litorâneas quaternárias do sudeste e sul do Brasil. Pp. 1-28. In: Anais do I Simpósio sobre Ecossistemas da Costa Sul e Sudeste Brasileira: síntese dos conhecimentos. Cananéia. São Paulo, ACIESP.

Suguio, K. \& Martin, L. 1990. Geomorfologia das Restingas. Pp. 185-205. In: Anais do II Simpósio de Ecossistemas da Costa Sul e Sudeste Brasileira: estrutura, função e manejo. v. 2. Águas de Lindóia. São Paulo, ACIESP.
Suguio, K. \& Tessler, M.G. 1984. Planícies de cordões litorâneos quaternários do Brasil: Origem e nomenclatura. Pp. 15-25. In. L.D. Lacerda; D.S.D. Araújo; R. Cerqueira \& B. Turq (orgs.). Restingas; origem, estrutura, processos. Niterói, CEUFF.

Sztutman, M. \& Rodrigues, R.R. 2002. O mosaico vegetacional numa área de floresta contínua da planície litorânea, Parque Estadual da Campina do Encantado, Pariquera-Açu, SP. Revista Brasileira de Botânica 25: 161-176.

Veloso, H.P.; Rangel Filho, A.L.R. \& Lima, J.C.A. 1991. Classificação da vegetação brasileira, adaptada a um sistema universal. Rio de Janeiro, IBGE.

Waechter, J.L. 1990. Comunidades vegetais das restingas do Rio Grande do Sul. Pp. 228-248. In: Anais do II Simpósio de Ecossistemas da Costa Sul e Sudeste Brasileira: estrutura, função e manejo. v. 3. Águas de Lindóia. São Paulo, ACIESP. 